\title{
Late Adolescence Mortality in Mice with Brain-Specific Deletion of the Volume- Regulated Anion Channel Subunit LRRC8A
}

Corinne S. Wilson ${ }^{1 *}$, Preeti Dohare ${ }^{1 *}$, Shaina Orbeta ${ }^{1}$, Russell J. Ferland ${ }^{2}$, Rajan Sah ${ }^{3}$, Annalisa Scimemi ${ }^{4 \S}$, Alexander A. Mongin ${ }^{1 \S}$

\author{
${ }^{1}$ Department of Neuroscience and Experimental Therapeutics, Albany Medical College, \\ Albany, NY, USA \\ ${ }^{2}$ Department of Biomedical Sciences, University of New England, Biddeford, ME, USA \\ ${ }^{3}$ Department of Internal Medicine, Washington University School of Medicine, St. Louis, MO, \\ USA \\ ${ }^{4}$ Department of Biology, University at Albany, State University of New York, Albany, NY, USA \\ ${ }^{*}$ Equal contribution co-first authors \\ §Equal contribution co-senior authors
}

Correspondence: Dr. Alexander A. Mongin, mongina@amc.edu

Competing interests: The Authors declare no competing interests.

Abbreviations: CA1-PCs, pyramidal cells of CA1 region; CNS, central nervous system; GAD, glutamate decarboxylase; GFAP, glial fibrillary acidic protein; IPSCs, inhibitory postsynaptic currents; LRRC8, leucine-reach repeat-containing family 8; MBP, myelin-basic protein; MPFA, multiple-probability fluctuation analysis; PTX, picrotoxin; PV, parvalbumin; VGAT, vesicular GABA transporter; VRAC, volume regulated anion channel 


\begin{abstract}
The leucine-rich repeat-containing family 8 member A (LRRC8A) is an essential subunit of the volume-regulated anion channel (VRAC). VRAC is indispensable for cell volume regulation but its broader physiological functions remain under investigation. Astrocyte-targeted Lrrc8a deletion in the nervous system reduces neuronal excitability, impairs synaptic plasticity and memory, and protects against ischemic damage. Here we show that deletion of LRRC8A in all brain cells, using Nestin ${ }^{\text {Cre }}$-driven $L r r c 8 a^{\text {fl/fl }}$ excision, is lethal. Mice devoid of brain LRRC8A are born close to the expected Mendelian ratio and develop without overt histological abnormalities. Nevertheless, they all die between 5 to 8 weeks of age with a seizure-like phenotype. Consistent with seizures, we found disruptions in cell excitability, GABAergic signaling, and astrocytic production of the GABA precursor glutamine, all of which might contribute to mortality. This work provides the first evidence of a critical role for VRAC in control of brain excitability during maturation.
\end{abstract}




\section{Introduction}

The volume regulated anion channel (VRAC) is a chloride/anion channel ubiquitously expressed in the majority of mammalian cells (Strange et al. 1996; Nilius et al. 1997; Okada 1997). The main established physiological role of VRAC is cell volume regulation. Cellular swelling, which occurs due to fluctuations in the extracellular osmolarity or to rises in the concentration of osmotically active molecules within the cell, triggers the opening of VRAC and increases the activity of several types of potassium channels (Lang et al. 1998; Hoffmann et al. 2009; Jentsch 2016). The ensuing VRAC-mediated fluxes of $\mathrm{Cl}^{-}$and $\mathrm{HCO}_{3}{ }^{-}$provide a countercharge for the loss of intracellular $\mathrm{K}^{+}$, leading to the dissipation of osmotic gradients and regulatory cell volume decrease. In addition to inorganic anions, VRAC is permeable to a large variety of small organic osmolytes, which are either negatively charged (e.g., the amino acids, glutamate and aspartate, and the carbohydrates, lactate and pyruvate), or net-neutral (e.g., the amino acids, alanine and glutamine, and the polyols, sorbitol and myo-inositol) (Strange et al. 1996; Nilius et al. 1997; Pedersen et al. 2016). The VRAC-mediated loss of organic osmolytes assists in cell volume control but may also play additional roles in cell-to-cell communication and other processes via the release of biologically active molecules (Wehner et al. 2003; Mongin 2016; Jentsch 2016; Strange et al. 2019).

Despite more than three decades of extensive biophysical and functional exploration, the identity of VRAC was uncovered only six years ago. In 2014, the laboratories of Ardem Patapoutian in the United States and Thomas Jentsch in Germany independently discovered that the leucine-rich repeat-containing protein $8 \mathrm{~A}$ (LRRC8A) is an essential component of VRAC (Qiu et al. 2014; Voss et al. 2014). LRRC8A belongs to a family of five mammalian proteins (LRRC8A-E) and their paralogues in other vertebrate species (Abascal and Zardoya 2012). LRRC8 proteins have sequence and structural homology to the channel and gap junctionforming pannexins and invertebrate innexins (Abascal and Zardoya 2012). The Jentsch group further established that in order to form fully functional VRAC channels, LRRC8A must partner with at least one additional member from the same family (LRRC8B-E) (Voss et al. 2014). Consistent with these findings, subsequent structural and mutagenesis studies confirmed that LRRC8 proteins form a hexameric assembly with one central pore and a relatively broad selectivity for various osmotically active molecules (Ullrich et al. 2016; Deneka et al. 2018; Kasuya et al. 2018; Yamada and Strange 2018; Kern et al. 2019). Depending on their subunit composition, LRRC8A-containing VRACs exhibit different biophysical properties, including relative permeability to inorganic anions and organic molecules (Planells-Cases et al. 2015; Gaitan-Penas et al. 2016; Schober et al. 2017). The existence of functionally distinct VRAC heteromers accounts for the previously reported cell type- and tissue-specific differences in VRAC properties.

Besides its well-accepted role in cell volume regulation, VRAC is thought to contribute to cell proliferation and migration, regulation of cell excitability and trans-epithelial transport, release of signaling molecules, and intercellular communication (Nilius et al. 1997; Hoffmann et al. 2009; Pedersen et al. 2016). Until recently, these additional functions were probed using poorly selective pharmacological blockers and correlative observations on changes in VRAC current densities (Pedersen et al. 2016; Mongin 2016; Strange et al. 2019). The discovery of the LRRC8 protein family prompted the use of more powerful genetic tools to identify the functional roles of different VRAC subunits. The first attempt to delete LRRC8A by Kumar et al. aimed at identifying the role of this protein in the immune system (Kumar et al. 2014). Their 
study generated a global deletion of $L r r c 8 a$, which resulted in significant embryonic mortality followed by a rapid demise of any live-born animals due to dramatic growth retardation and multiple organ failure (Kumar et al. 2014). Therefore, subsequent studies employed conditional, region- and cell type-specific Lrrc8a gene deletion. This approach revealed tissue-specific contributions of VRAC to reproductive function (spermatogenesis), regulation of adipocyte size, insulin signaling, glucose homeostasis, and innate immunity (Luck et al. 2018; Bao et al. 2018; Zhang et al. 2017; Kang et al. 2018; Zhou et al. 2020). Although the central nervous system (CNS) has long been considered to be the tissue with the highest sensitivity to cell volume alterations and VRAC activity (Kimelberg and Mongin 1998; Kimelberg 2005; Mongin 2007; Mongin 2016; Wilson and Mongin 2018), few studies have analyzed the functional significance of LRRC8 proteins in the brain. Our group was the first to uncover a key role for LRRC8Acontaining channels in swelling- and agonist-activated release of excitatory neurotransmitters from astrocytes and explore the molecular composition of the endogenous LRRC8 heteromers in brain cells (Hyzinski-Garcia et al. 2014; Schober et al. 2017). More recent seminal work by Zhaozhu Qiu and coworkers produced the first conditional deletion of VRAC in the CNS. Their

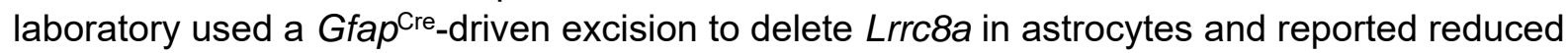
hippocampal excitability, impaired long-term potentiation (LTP), spatial and contextual learning deficits, and resistance to cerebral ischemia (Yang et al. 2019).

Besides the above-mentioned astrocytic deletion of $L r r c 8 a$, the functional impact of LRRC8-containing channels in the CNS is yet to be explored. In the present work, we produced a whole-brain deletion of $L r r c 8 a$, using the nestin promoter-driven expression of Cre recombinase. Nestin ${ }^{\mathrm{Cre} /+}$; LrrC8 $\mathrm{a}^{\text {fl/fl }}$ mice (here referred to as LRRC8A KO) developed normally but all died at 5 to 8 weeks of age, while showing changes in hippocampal cell excitability and GABAergic transmission, and overt seizures. Thus, our study provides important evidence for the crucial role of VRAC in CNS function via regulation of brain excitability during early-to-late adolescence.

\section{Results}

\section{Brain-specific deletion of LRRC8A causes seizures and mortality in late adolescence}

We generated a whole-brain deletion of the essential VRAC protein LRRC8A by breeding Lrrc8a fl/fl mice (originally characterized in a previous study (Zhang et al. 2017)) with Nestin ${ }^{\mathrm{Cre} /+} ; \mathrm{LrrCB}^{\mathrm{fl} /+}$ mice. Nestin, an intermediate filament protein, is expressed in developing mouse embryos as early as E7.5 and is enriched in neural stem cells throughout development and into adulthood (Dahlstrand et al. 1995; Lagace et al. 2007). Nestin promoter-driven Cre targets all classes of brain neuroectodermal cells, including neurons, astrocytes and oligodendrocytes, and is used for whole-brain modifications of gene expression (Tronche et al. 1999; Dubois et al. 2006). Our breeding scheme and the four genotypes obtained from this strategy are described in Fig. $1 \mathrm{~A}$. This breeding strategy has been designed to yield a high number of knockout mice (Nestin ${ }^{\mathrm{Cre} /+} ; \mathrm{LrCBa}^{\mathrm{fl} / \mathrm{fl}},[\mathrm{KO}]$ ) and does not generate $\mathrm{LrCBO}^{+/+}$or Nestin Cre/+ progeny. We used age-matched Lrrc8a ${ }^{\mathrm{fl} /+}(\mathrm{fl} /+), \operatorname{LrrCBa}^{\mathrm{fl} / \mathrm{fl}}(\mathrm{fl} / \mathrm{fl})$, and Nestin ${ }^{\mathrm{Cre} /+} ; \mathrm{LrrC}^{\mathrm{f}} \mathrm{a}^{\mathrm{fl} /+}$ (Het) littermates as internal controls.

To validate the successful deletion of the targeted protein, we performed semi-quantitative western blot analysis in brain lysates and found a complete absence of LRRC8A immuno- 
reactivity in the LRRC8A KO brains (Fig. 1B; the complete set of full-length western blot images in Suppl. Fig. 1.1). As a control, we analyzed LRRC8A expression in the heart, kidney, liver and lung tissues, and found no significant changes in relative LRRC8A protein levels (Suppl. Fig. 1.2). We further compared the levels of LRRC8A protein expression in primary astrocyte cultures prepared from neonatal brains of all four genotypes and confirmed the loss of LRRC8A in the LRRC8A KO cells (Suppl. Fig. 1.3). Functional deletion of LRRC8A-containing VRAC was validated in a radiotracer efflux assay, which measures the swelling-activated release of the glutamate analogue $\mathrm{D}-\left[{ }^{3} \mathrm{H}\right]$ aspartate from cultured astrocytes exposed to a $30 \%$ reduction in medium osmolarity (Fig. 1C). Our prior RNAi experiments in rat astrocytes proved that such release is mediated by the LRRC8A-containing VRAC, and represents a functional equivalent of swelling activated $\mathrm{Cl}^{-}$currents (Abdullaev et al. 2006; Hyzinski-Garcia et al. 2014; Schober et al. 2017). The advantage of this approach is that it allows for analysis of VRAC activity in intact cells and on a populational rather than single-cell level. Swelling-activated radiotracer release was significantly reduced in LRRC8A KO astrocytes ( $70 \%$ inhibition of the maximal release rates and $>80 \%$ drop in stimulated integral release values), validating the loss of VRAC activity in LRRC8A KO animals (Fig. 1C). The small residual swelling-activated glutamate release showed different kinetic properties (rapid inactivation, Fig. 1C) and was likely mediated by an alternative, swelling-activated release pathway. Together, these results indicate that there is a brain-specific loss of LRRC8A protein and VRAC activity in Nestin ${ }^{\mathrm{Cre} /+} ;$ LrrC8a $^{\mathrm{fl} / \mathrm{fl}}$ (LRRC8A KO) mice.

The previously characterized global LRRC8A KO mice show pronounced embryonic lethality, dramatic growth retardation, and die from multiple organ failure(Kumar et al. 2014). In contrast, mice with brain-specific loss of Lrrc8a were born with the expected Mendelian ratio of $25 \%$ (23\%, 54/235 mice, no different, Chi-squared test, Fig. 1A) and developed normally

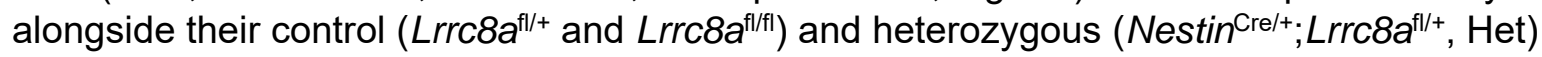
littermates. We found no gross neuroanatomical or cytoarchitectural abnormalities in the forebrain (thionin staining in Fig. 1D, see Suppl. Fig. 1.4 for extended analysis). Neither did we detect any gross defects in body anatomy (Fig. 1E) or changes in weight gain in mice of both sexes (Fig. 1F, and extended analysis in Suppl. Fig. 1.5).

Despite their apparently normal development, LRRC8A KO mice began dying during postnatal weeks 4 and 5 and all remaining mice died between postnatal weeks $6-8$, which approximately corresponds to puberty and late adolescence in humans, respectively(Schneider 2013). None of the knockout animals survived past the beginning of week 9 (see the KaplanMeier survival curve in Fig. 1G, note that the curve is censored for animals euthanized for experimental analysis). Observations of animals showed that LRRC8A KO mice had seizures. Two major types of seizures were seen in these mice: (1) generalized clonic seizures, consisting of forelimb and/or hindlimb clonus with or without loss of posture control, and (2) generalized clonic seizures with loss of posture that immediately transitioned into brainstemtonic seizures consisting of wild-running and popcorning (Suppl. Media Files 1 and 2). Some mice had repeated seizures during the observation period. While long-term monitoring was not conducted, $15 \%$ of mice were observed having seizures during cage checks or behavioral testing, which clearly only accounts for a small percentage of time during the day. No seizures were ever observed in control mice $\left(L r r c 8 a^{\mathrm{fl} /+}[\mathrm{fl} /+]\right.$ and $\left.L r r c 8 a^{\mathrm{fl} / \mathrm{fl}}[\mathrm{fl} / \mathrm{fl}]\right)$ or in mice carrying the heterozygous LrrC8a deletion (Nestin $\left.{ }^{\mathrm{Cre} /+} ; \mathrm{LrCB}^{\mathrm{fl} /+}[\mathrm{Het}]\right)$. These findings are consistent with our previous work in which mice treated with flurothyl displayed seizures during long-term videoEEG recordings, but never during handling or cage checks(Kadiyala et al. 2016). This would 
suggest the likelihood that many of the LRRC8A KO mice are having seizures in their home cages that simply go unnoticed, and that could eventually result in sudden expected death (see discussion). Lastly, gross anatomical evaluation did not reveal any obvious bleeding abnormalities in the brain or defects of major organs in the chest cavity that could account for alternative mechanisms of the death of LRRC8A KO mice.

\section{Lrrc8a knockout animals display astrogliosis, but no changes in numbers of neurons, astrocytes, or oligodendrocytes}

As the Nestin Cre-driven deletion of Lrrc8a targets all cells derived from neural precursors, we examined whether VRAC deletion leads to changes in the numbers of neurons, astrocytes, and/or oligodendrocytes. To this end, we used immunohistochemical analysis and counted the numbers of cells immunolabelled for the neuronal marker NeuN (Fig. 2A), the astrocytic marker GFAP (Fig. 2B), and the oligodendroglial marker myelin-basic protein (MPB, Fig. 2C). In all cases, the statistical comparisons were done across all four genotypes. The number of NeuNpositive cells was quantified in a defined, representative region of interest in the cortex above the hippocampal CA1 region and showed no differences across the four genotypes (Fig. 2A4). There were no changes in the numbers of GFAP-positive astrocytes, quantified in the hippocampus (Fig. 2B3). Due to low GFAP expression in cortex, accurate counts of cortical astrocytes could not be performed. Interestingly, although the numbers of GFAP-positive astrocytes in the hippocampus did not differ among the four genotypes, we detected a significant increase in GFAP intensity in LRRC8A KO specimens, which is often a measure of reactive gliosis (Compare Fig. 2B1 and 2B2 and high magnification insets). When GFAP immunoreactivity was quantitatively compared with matched settings and within the sets immunostained at the same time, average normalized intensity levels in LRRC8A KO sections were increased by $>50 \%$ (Fig. 2B4), and analysis of LRRC8A KO brains at higher magnification revealed hypertrophied astrocytes (inset in Fig. 2B2). Whether this is inherent to LRRC8A KO or a result of potential seizure activity is not clear. However, the reactive gliosis was causally linked to disruptions in inhibitory signaling in the hippocampus (see (Ortinski et al. 2010) and Discussion). To assess oligodendroglia, we stained brain sections for MBP and quantified the thickness and length of the corpus callosum, a major myelinated tract in the brain (Fig. 2C). We found no changes in average corpus callosum thickness (Fig. 2C3) or length (Fig. 2C4) in LRRC8A KO mice. The average fluorescence intensity of MBP in the cortex or striatum did not differ (Suppl. Fig. 3.1). Overall, these findings suggest that deletion of Lrrc8a does not impact the numbers of neurons, astrocytes, oligodendrocytes, or the degree of myelination. The lack of changes in the CNS is somewhat surprising because VRAC was proposed to regulate cell proliferation, migration, differentiation, and survival in many cell types (reviews (Nilius et al. 1997; Lang et al. 1998; Hoffmann et al. 2009) and recent experimental studies (Kumar et al. 2014; Bao et al. 2018; Chen et al. 2019)).

\section{Behavioral changes in mice with brain specific Lrrc8a deletion}

We planned four behavioral assays on mice aged 6-7 weeks. Only two assays were completed due to animal mortality. We used the open field and elevated plus maze tests to measure locomotion and anxiety-like behaviors in control and LRRC8A KO mice (see Fig. 3 and extended analysis in Suppl. Fig. 3.1). In the open field test, LRRC8A KO animals spent 
significantly less time in the center of the open field arena (Fig. 3A, B), but displayed no reduction in locomotor activity (Fig. 3C), suggesting an anxiety phenotype. However, this conclusion was not supported by the outcomes of the elevated plus maze test. In the latter assay, LRRC8A KO mice did not show any significant decrease in the number of entries into the open arms and thus did not display an anxiety-like phenotype as compared to controls and the animals with heterozygous LRRC8A deletion (Fig. 3D, E). Again, there were no changes in the total distance travelled between all four genotypes (Fig. 3F). To assure that inconsistencies between the two behavioral assessments are not due to visual impairment, we examined mice in the Morris Water Maze (MWM) test. During the first day of visual MWM training, LRRC8A KO mice were able to recognize the platform and improve their performance over the subsequent trials (Suppl. Fig. 3.2). Unfortunately, the full learning and memory retention testing could not be completed due to early lethality. Overall, behavioral experiments demonstrate some alterations but no strong behavioral phenotype in LRRC8A KO mice. In addition, there were no differences between male and female mice (post hoc analysis Suppl. Fig. 3.1).

\section{Electrophysiological analysis in hippocampal slices reveals reduced excitability of CA1 pyramidal cells in LRRC8A KO mice}

Since spontaneous seizure activity was observed in mice with brain-specific deletion of Lrrc8a, we asked whether this could be due to changes in cell excitability in the hippocampus, a brain region implicated in seizure generation (Sloviter 1987; Magloczky and Freund 2005). To this end, we performed whole-cell patch-clamp recordings from CA1 pyramidal cells (CA1-PCs) in acute hippocampal slices from 5-7 week-old LRRC8A KO mice. Lrrc8a $a^{\mathrm{fl} /+}$ and $L r r c 8 a^{\mathrm{fl} / \mathrm{fl}}$ mice were used as combined controls. Our first experiments aimed to identify changes in the passive and active membrane properties of CA1-PCs (Fig. 4A,B), the main output neurons of the hippocampus. There were no statistically significant changes in the membrane resistance (Fig. 4B1) and resting membrane potential across genotypes (Fig. 4B2), and therefore the holding current necessary to keep these cells at a potential of $-70 \mathrm{mV}$ was similar across all tested genotypes (Fig. 4B3). In separate current clamp experiments, we maintained all cells at -70 $\mathrm{mV}$ using $\mathrm{DC}$ current injections and delivered 5-ms positive current steps of increasing amplitude to evoke single action potentials (Fig. 4C, D). The rheobase, which represents the amplitude of the smallest current step able to elicit an action potential, was larger in CA1-PCs from LRRC8A KO mice (Fig. 4D1). The threshold for action potential generation was more depolarized in LRRC8A KO mice (Fig. 4D2), as was the peak of the action potential (Fig. 4D3). These findings suggest the existence of differences in the activation and/or biophysical properties of voltage-gated sodium and potassium channels in CA1-PCs devoid of LRRC8A protein, which ultimately dampen the excitability of these cells.

To determine how these changes in cell excitability affect sustained firing of CA1-PCs, we applied longer (500 ms) supra-threshold current steps (Fig. 4E). The firing rate-current plots showed that the firing rate of CA1-PCs in LRRC8A KO mice was smaller than in control (fl/+ and $\mathrm{fl} / \mathrm{fl}$ ) mice over a range of positive current injections, leading to a rightward shit in the $\mathrm{f} / \mathrm{l}$ plots (Fig. 4F). Together, these results suggest that loss of LRRC8A protein and VRAC activity impairs the excitability of CA1-PCs, with potential consequences on information flow in and out of the hippocampus. Unfortunately, early mortality did not allow us to find behavioral correlates of these phenomena. 


\section{Lrrc8a deletion modifies GABAergic inhibition onto CA1 pyramidal cells}

Action potentials of CA1-PCs are shaped by their ability to integrate in space and time both excitatory and inhibitory synaptic inputs. Therefore, we performed experiments to identify changes in excitatory and inhibitory synaptic transmission in the CA1 region of LRRC8A KO mice. We first performed extracellular field recordings from the stratum radiatum. Here, a recording electrode and a bipolar stimulating electrode were both placed in the stratum radiatum, 100-150 $\mu \mathrm{m}$ away from each other (Fig. 4G). Schaffer collateral stimulation evoked a complex waveform composed of a fast-rising and fast-decaying fiber volley (FV), followed by a slow-decaying field post-synaptic potential (fPSP; Fig. 4H). The FV amplitude provides a proxy readout of the number of activated afferent fibers. Therefore, by measuring the ratio between the fPSP slope and the FV amplitude, we measured the magnitude of the post-synaptic response for a given number of activated afferent fibers. This ratio was similar in control and LRRC8A KO mice (Fig. 4H). Blocking $\mathrm{GABA}_{\mathrm{A}}$ receptors with picrotoxin (PTX, $100 \mu \mathrm{M}$ ) caused a significant increase in the fEPSP/FV ratio in control ( $\mathrm{fl} /+$ and $\mathrm{fl} / \mathrm{fl})$ and $\mathrm{LRRC} 8 \mathrm{~A}$ KO mice. The effect of picrotoxin was similar across these genotypes (Fig. 4I). Together, these results suggest that LRRC8A deletion produces no overt change in the strength of fast glutamatergic transmission at Schaffer collateral synapses and in its susceptibility to GABAergic inhibition (but see the detailed analysis below).

The latter results do not rule out the possibility that more subtle changes in GABAergic inhibition may occur at inhibitory synapses onto CA1-PCs. For this reason, we performed whole-cell recordings in voltage-clamp mode to record inhibitory postsynaptic currents (IPSCs) from CA1-PCs. We isolated these GABAergic IPSCs pharmacologically by adding the AMPA receptor antagonist NBQX and the NMDA receptor antagonist APV to the extracellular solution. In cells held at $0 \mathrm{mV}$ (the estimated reversal potential for glutamatergic currents), stimulation of Schaffer collaterals produced outward IPSCs (Fig. 4K). The IPSC amplitude increased exponentially when increasing the extracellular calcium concentration from 0.5 to $4 \mathrm{mM}$, consistent with previous work (Dodge, Jr. and Rahamimoff 1967). This relationship, however, differed between control (fl/t+ and fl/fl) and LRRC8A KO mice (Fig. 4K). This effect is unlikely to be accounted for by changes in release probability, because it was not associated with significant changes in the IPSC paired-pulse ratio $\left(\left[\mathrm{Ca}^{2+}\right]_{0}=2 \mathrm{mM} \mathrm{PPR}\right.$ control: $0.88 \pm 0.07(n=7)$, $\left.P_{\text {PRo: }} 1.05 \pm 0.08(n=14), p=0.12\right)$. The trial-to-trial amplitude fluctuations in IPSC amplitude contain information about the quantal parameters, $N$ (the number of release sites), $P_{r}$ (the release probability), and $Q$ (the quantal size). Multiple-probability fluctuation analysis (MPFA) provides a method for estimating the quantal parameters $N$ and $Q$ from the IPSC variance and mean, under a range of release probability conditions that can be obtained by changing the extracellular concentration of calcium (Silver et al. 1998; Clements and Silver 2000; Silver 2003). One of the main strengths of the MPFA analysis is that it does not rely on assumptions of uniform release probability distribution across release sites, which might occur at hippocampal inhibitory synapses. By using the MPFA analysis, we detected a modest increase in the number of active release sites coupled with a pronounced decrease in the mean quantal size of GABAergic IPSCs in LRRC8A KO mice (Fig. 4L). Together, these results suggest that there are notable functional changes in the properties of GABA release from inhibitory neurons onto CA1-PCs, which cannot be detected using extracellular field recordings (for functional implications see Discussion). 


\section{LRRC8A deletion produces no changes in GABAergic cell markers or in the numbers of parvalbumin-positive interneurons}

To determine whether there was any dysfunction in GABA synthesis or vesicular loading of GABA, changes in protein expression of glutamic acid decarboxylase isoforms (GAD65/67) and vesicular GABA transporter (VGAT) were examined. The semi-quantitative western blotting showed no differences in the expression of GAD65/67 or VGAT proteins in whole-brain protein lysates (Fig. 5B, C). GAD65/67 are often used as marker for inhibitory interneurons, and the lack of changes in their expression levels suggests that deletion of Lrrc8a causes no gross changes in number of interneurons. To further explore potential differences in interneuron populations, we immunolabeled and counted parvalbumin-positive cells in the CA1 pyramidal cell layer (Fig. 5E) or in the cerebral cortex above the hippocampus in the same slices (Fig. 5D). Quantitative analysis revealed no significant changes in either of the analyzed brain regions (Fig. 5D3, E3).

\section{Downregulation of glutamine synthetase and modifications in neurotransmitter levels in Lrrc8a-null brains}

GABA levels in the brain are largely maintained by GAD65/67-catalyzed synthesis from glutamate, whose presynaptic levels are sustained by the export of glutamine from the surrounding astrocytes (see Fig. 6A and review (Coulter and Eid 2012)). Therefore, we quantified the levels of the glutamine-producing enzyme, glutamine synthetase. In three-weekold primary astrocyte cultures, we found a dramatic loss of glutamine synthetase immunoactivity in LRRC8A KO cultures as compared to the matching cultures prepared from two control genotypes and heterozygous Lrrc8a deletion (Fig. 6B, full blots in Suppl. Fig. 6.1). This loss of glutamine synthetase enzyme levels was not fully recapitulated in the analysis of brain lysates (Fig. 6C, full blots in Suppl. Fig. 6.1). Nevertheless, we found statistically significant reductions in the whole-brain levels of glutamine (Fig. 6D3) and alanine (Fig. 6D5) in LRRC8A KO animals, as determined by HPLC analysis, and compared to $\mathrm{LrCBO}^{\mathrm{fl} /+}$ controls and $\mathrm{Nestin} \mathrm{Crel+}_{;} \mathrm{LrrC}^{\mathrm{fl} /++}$ heterozygotes (Het). In the brain, alanine synthesis and transport are known to be connected to processes involving both GABAergic and glutamatergic signaling via transamination and the lactate-alanine shuttle(Schousboe et al. 2003; Bak et al. 2006). There were no statistically significant changes in the levels of glutamate (Fig. 6D2) or GABA (Fig. 6D6), but this may be due to homeostatic regulation or experimental variability. One striking observation was that LRRC8A deletion led to a significant increase ( $60 \%)$ in brain levels of taurine (Fig. 6D4, and Suppl. Fig. 6.3). To the best of our knowledge, there is no metabolic connection between production of taurine and GABA, glutamate, and glutamine. However, because taurine acts as an endogenous agonist at $\mathrm{GABA}_{\mathrm{A}}$ and glycine receptors (El and Trenkner 2004; Albrecht and Schousboe 2005), its increase may represent a compensatory mechanism. Overall, western blot and HPLC analyses suggest reduced astrocytic export of glutamine as a potential cause for the reduced GABAergic signaling and perhaps seizure development observed in LRRC8A KO mice (see Discussion). 


\section{Discussion}

The most striking observation of our work is the $100 \%$ lethality in early to late adolescence in mice with brain-specific deletion of the LRRC8A protein. None of the LRRC8A KO animals survived past the beginning of postnatal week nine. The severity of this phenotype loosely resembles the dramatic embryonic and early postnatal mortality observed in mice with global deletion of Lrrc8a, who die due to severe defects in multiple organs (Kumar et al. 2014). However, our brain-specific LRRC8A KO mice developed apparently normally and then died suddenly. Notably, our findings are in contrast with the study of Yang et al. that produced the first conditional deletion of LRRC8A in the brain, using the relatively astrocyte-selective GFAP promoter (Yang et al. 2019). In their publication, removal of astrocytic LRRC8A reduced neuronal excitability, impaired long-term potentiation and learning, and protected against experimental stroke; however, no increased mortality or developmental abnormalities in the CNS were reported (Yang et al. 2019). These latter findings are consistent with the longstanding idea that astrocytic VRAC promotes neuronal excitability and brain damage via physiological and pathological release of the excitatory amino acid transmitters, aspartate and glutamate (Kimelberg and Mongin 1998; Kimelberg 2005; Mongin 2016; Mongin 2007). Because our current deletion strategy targeted all three major types of brain cells, we anticipated to find a more pronounced neurological phenotype, reduced excitation, and perhaps developmental defects. Yet, until the time of mouse death, LRRC8A KO brains developed apparently normally. We found no gross changes in brain anatomy or numbers of neuronal, astroglial, or oligodendroglial cells by the end of postnatal week six (timing of histological analyses). Despite this, a significant fraction of the LRRC8A KO mice developed overt seizures, which we observed during behavioral testing and animal handling. Although the direct link between this seizure phenotype and animal death has not been tested, it is highly likely that the observed changes in neuronal excitability were the contributing factor to mortality. In fact, some of the observed seizures in LRRC8A KO mice were of a brainstem-tonic manifestation, suggesting the possibility that ictal discharge propagating to the brainstem could be causing aberrant physiological activity in brainstem regions important for life (i.e., respiratory and cardiac centers). Anomalous activity in the brainstem has been implicated in causing sudden unexpected death in human epilepsy and mouse epilepsy models (e.g., (Aiba and Noebels 2015)).

Pinpointing the cellular and molecular mechanism(s) for changes in neuronal excitation proved to be difficult. We started by measuring neuronal excitability in the CA1 region of the hippocampus. Whole-cell recordings in CA1 pyramidal neurons revealed modest reductions in cell excitability. This effect, on its own, is unlikely to account for the onset of seizures due to brain-wide loss of $L r r c 8 a$. Therefore, in search for a cause of seizures, we next probed for changes in synaptic transmission. Electrophysiological recordings of the extracellular field potentials evoked by Schaffer collateral stimulation of hippocampal stratum radiatum did not identify major differences in excitatory and inhibitory synaptic strength. Accordingly, the field recordings showed a similar sensitivity to blockade of GABA receptors with $\mathrm{PTX}$ in control and Lrrc8a-null mice, suggesting that the overall effect of GABAergic inhibition is preserved. By using single-cell recordings, however, we showed that there is a marked reduction in the quantal size of GABAergic IPSCs in LRRC8A KO mice. This effect is associated with a modest increase in the number of active release sites in LRRC8A KO. The results of the MPFA analysis prompted us to analyze the expression levels for the GABA-producing enzymes, GAD65/67, and the GABA packaging vesicular transporter, VGAT. Semi-quantitative western 
blotting identified no obvious changes in the levels of these proteins in whole-brain protein lysates. We also found no evidence for differences in the densities of inhibitory neuron subpopulations by looking at the average numbers of parvalbumin-positive cells in the CA1 pyramidal cell layer and adjacent cerebral cortex. These negative results are consistent with the lack of apparent histological alterations and unchanged numbers of NeuN-positive cells in the Lrrc8a-null brains. Nevertheless, they do not exclude the possibility of functional defects in inhibitory transmission. Although early human and animal studies found no significant loss in total numbers of hippocampal GABAergic cells, they nevertheless demonstrated reduced GABA release and loss of plasmalemmal GABA transporters (During et al. 1995). Furthermore, subsequent detailed work in epileptogenesis models identified a more nuanced loss in select populations of interneurons, including region-specific changes in parvalbumin-positive cells (reviewed in (Magloczky and Freund 2005)).

In search of a molecular mechanism for modified GABAergic signaling, we turned to the brain glutamine-glutamate/GABA cycle. In the CNS, both glutamatergic and GABAergic neurons use astrocyte-derived glutamine for the synthesis of glutamate and GABA, respectively(Bak et al. 2006; McKenna 2007). Production of GABA consumes between 10-25\% of glutamine flow (Patel et al. 2005; Hertz 2013), and is highly sensitive to inhibition of any step of the glutamine-glutamate cycle (Liang et al. 2006; Fricke et al. 2007). Numerous reports linked the loss or inhibition of the astrocytic glutamine synthetase to hyperexcitation and the development of low-grade status epilepticus (Eid et al. 2008; Wang et al. 2009; Perez et al. 2012), and proposed the loss of the glutamine synthetase protein as a potential cause of human temporal lobe epilepsy (Eid et al. 2004). One mouse study linked the induction of reactive gliosis with downregulation of glutamine synthase and a deficit in inhibitory, but not excitatory synaptic function (Ortinski et al. 2010). The latter finding is noteworthy because of the reactive gliosis that we found in LRRC8A KO brains. Also relevant, the maturation of the glutamineglutamate cycle in mice happens postnatally and is completed by, or after, week four (Chowdhury et al. 2007; Hertz 2013), which precedes the onset of mortality in our transgenic animals. In this context, we found a remarkably strong loss of glutamine synthetase immunoreactivity in primary astrocytes prepared from neonatal LRRC8A KO brains. Although western blot analysis did not show statistically significant reductions in total brain glutamine synthetase levels, we did find lower whole-brain glutamine content in the LRRC8A KO tissue as compared to the control $L r r c 8 a^{f / /+}$ brains and brains with heterozygous $L r r c 8 a$ deletion. Very similar moderate decreases in glutamine synthesis, with no matching decreases in whole-brain GABA levels, have been found in animals with kainate-induced epilepsy (Alvestad et al. 2008). Furthermore, model electrophysiological work in hippocampal slices found that the drop in glutamine import by GABAergic neurons initially produces no effects on "baseline" inhibitory signaling, but strongly impairs GABAergic drive after a period of synaptic activity(Liang et al. 2006). Significantly, the latter study found reduced quantal release at individual GABAergic synapses as a function of reduced glutamine import (Liang et al. 2006). It is tempting to draw a parallel between these published results and our own MPFA data and conclude that inhibition of glutamine synthesis is responsible for the reduced GABAergic tone and animal seizures/mortality.

An additional mechanism that can contribute to hyperexcitability is the failure of dynamic control of cellular volume and extracellular space. During development, the volume of extracellular space in the brain is reduced progressively and significantly to an average value of $\sim 20 \%$ of the total brain volume in adulthood (reviewed in (Sykova and Nicholson 2008)). 
However, the volume of brain interstitial space does not stay constant and is dynamically reduced during neuronal excitation, mostly due to the swelling of astrocytes which accumulate ions and neurotransmitters (e.g., (Svoboda and Sykova 1991; Andrew and MacVicar 1994; Holthoff and Witte 1996; Haj-Yasein et al. 2012), and reviews (Sykova and Nicholson 2008; Wilson and Mongin 2018)). Deletion of LRRC8A-containing VRAC results in the loss of cell volume regulation, including in brain cells (Qiu et al. 2014; Voss et al. 2014; Formaggio et al. 2019), and may blunt homeostatic control of extracellular space. The persistent cellular swelling during periods of enhanced neuronal activity is sufficient to produce hyperexcitation due to changes in the extracellular $\mathrm{K}^{+}$and excitatory neurotransmitter levels (Wilson and Mongin 2018; Murphy et al. 2017). In fact, such swelling has been proposed as an important driving cause in epileptogenesis (Traynelis and Dingledine 1989; Andrew 1991; Binder et al. 2004; Murphy et al. 2017; Wilson and Mongin 2018). This mechanism would be strongly underestimated in brain slice preparations because they have no limitations for activity-dependent tissue expansion. Unfortunately, quantification of changes in the extracellular space in the intact tissue is quite challenging.

In conclusion, we established that the LRRC8A-containing volume-regulated anion channels are dispensable for normal brain development but contribute critically to the control of brain tissue excitability in adolescence. Mice with the brain-wide deletion of the essential VRAC subunit, LRRC8A, in neurons, astrocytes and oligodendrocytes, develop a seizure phenotype and all die in early-to-late adolescence. We identified mild changes in cell excitability and GABAergic transmission, low-grade reactive astrogliosis in the hippocampus, and a decrease in the tissue level of the GABA precursor, glutamine. These findings suggest that the disruption in the glutamine-glutamate/GABA cycle between astrocytes and neurons, causing reductions in GABA supply, might lead to changes in GABAergic inhibition and animal death. 


\section{Materials and methods}

\section{Key resources table:}

\begin{tabular}{|c|c|c|c|c|}
\hline $\begin{array}{l}\text { Reagent type } \\
\text { (species) or } \\
\text { resource }\end{array}$ & Designation & $\begin{array}{l}\text { Source or } \\
\text { reference }\end{array}$ & Identifiers & $\begin{array}{l}\text { Additional } \\
\text { information }\end{array}$ \\
\hline $\begin{array}{l}\text { Strain, strain } \\
\text { background } \\
\text { (M. musculus) }\end{array}$ & $\begin{array}{l}\operatorname{Lrrc8}^{\mathrm{fl} / \mathrm{fl}}(\text { Swell/1//fl}) \\
\text { mice }(\mathrm{C} 57 \mathrm{BL} / 6 \mathrm{~J} \\
\text { background })\end{array}$ & $\begin{array}{l}\text { PMID: } \\
28436964\end{array}$ & & $\begin{array}{l}\text { Shared by Dr. } \\
\text { Rajan Sah }\end{array}$ \\
\hline $\begin{array}{l}\text { Strain, strain } \\
\text { background } \\
\text { (M. musculus) }\end{array}$ & $\begin{array}{l}\text { (B6.Cg-Tg(Nes- } \\
\text { cre) } 1^{K / n} / \mathrm{J}\end{array}$ & $\begin{array}{l}\text { Jackson } \\
\text { Laboratory }\end{array}$ & stock \#003771 & \\
\hline $\begin{array}{l}\text { Strain, strain } \\
\text { background } \\
\text { (M. musculus) }\end{array}$ & Nestin $^{\mathrm{Cre} /+} ; \mathrm{LrrC} \mathrm{a}^{\mathrm{fl} /+}$ & This paper & & $\begin{array}{l}\text { Heterozygous } \\
\text { deletion of } \\
\text { LRRC8A }\end{array}$ \\
\hline $\begin{array}{l}\text { Strain, strain } \\
\text { background } \\
\text { (M.musculus) }\end{array}$ & Nestin $^{\mathrm{Cre} /+} ;$ LrrC8a $^{\mathrm{fl} / \mathrm{fl}}$ & This paper & & $\begin{array}{l}\text { Brain-specific } \\
\text { LRRC8A knockout }\end{array}$ \\
\hline $\begin{array}{l}\text { Cell line } \\
\text { (M. musculus) }\end{array}$ & $\begin{array}{l}\text { Cultured primary } \\
\text { astrocytes }\end{array}$ & This paper & & $\begin{array}{l}\text { Prepared from four } \\
\text { genotypes }\end{array}$ \\
\hline Antibody & $\begin{array}{l}\text { Mouse } \\
\text { monoclonal glial } \\
\text { fibrillary acidic } \\
\text { protein (GFAP) }\end{array}$ & Millipore-Sigma & cat. \# G5163 & $\begin{array}{l}\text { IHC dilution: } \\
1: 400\end{array}$ \\
\hline Antibody & $\begin{array}{l}\text { mouse } \\
\text { monoclonal anti- } \\
\text { LRRC8A }\end{array}$ & Santa Cruz & $\begin{array}{l}\text { cat. \# sc- } \\
517113\end{array}$ & $\begin{array}{l}\text { WB dilution: } \\
1: 500\end{array}$ \\
\hline Antibody & $\begin{array}{l}\text { rabbit polyclonal } \\
\text { anti-GAD65/67 }\end{array}$ & Millipore-Sigma & cat. \# G5163 & $\begin{array}{l}\text { WB dilution: } \\
1: 2,000\end{array}$ \\
\hline Antibody & $\begin{array}{l}\text { rabbit polyclonal } \\
\text { anti-VGAT }\end{array}$ & Invitrogen & $\begin{array}{l}\text { cat. \#Pa5- } \\
27569\end{array}$ & $\begin{array}{l}\text { WB dilution: } \\
1: 1000\end{array}$ \\
\hline Antibody & $\begin{array}{l}\text { rabbit polyclonal } \\
\text { anti-glutamine } \\
\text { synthetase }\end{array}$ & Millipore-Sigma & cat. \#G2781 & $\begin{array}{l}\text { WB dilution: } \\
1: 20,000\end{array}$ \\
\hline Antibody & $\begin{array}{l}\text { horseradish } \\
\text { peroxidase (HRP)- } \\
\text { conjugated } \\
\text { antibody: donkey } \\
\text { anti-rabbit }\end{array}$ & GE Healthcare & cat. \#NA932 & $\begin{array}{l}\text { Secondary Ab, } \\
\text { WB dilution: } \\
1: 10,000\end{array}$ \\
\hline Antibody & $\begin{array}{l}\text { HRP-conjugated } \\
\text { sheep anti-mouse } \\
\text { lgG }\end{array}$ & GE Healthcare & cat \#NA931 & $\begin{array}{l}\text { Secondary Ab, } \\
\text { WB dilution: } \\
1: 10,000\end{array}$ \\
\hline Antibody & $\begin{array}{l}\text { HRP-conjugated } \\
\text { primary anti- } \beta \text { - } \\
\text { actin antibody }\end{array}$ & Millipore-Sigma & cat. \#A-3854 & $\begin{array}{l}\text { WB dilution } \\
1: 50,000\end{array}$ \\
\hline Antibody & $\begin{array}{l}\text { Rabbit polyclonal } \\
\text { anti-GAPDH }\end{array}$ & Millipore-Sigma & cat. \#G9545 & $\begin{array}{l}\text { WB dilution: } \\
1: 10,000\end{array}$ \\
\hline
\end{tabular}




\begin{tabular}{|c|c|c|c|c|}
\hline Antibody & $\begin{array}{l}\text { rabbit polyclonal } \\
\text { anti- } \\
\text { RBFOX3/NeuN }\end{array}$ & $\begin{array}{l}\text { Novus } \\
\text { Biologicals }\end{array}$ & $\begin{array}{l}\text { cat. \#NBP1- } \\
77686\end{array}$ & $\begin{array}{l}\text { IHC dilution: } \\
1: 200\end{array}$ \\
\hline Antibody & $\begin{array}{l}\text { mouse } \\
\text { monoclonal anti- } \\
\text { MBP }\end{array}$ & Biolegend & cat. \#SMI-99P & $\begin{array}{l}\text { IHC dilution: } \\
1: 1,000\end{array}$ \\
\hline Antibody & $\begin{array}{l}\text { guinea pig } \\
\text { polyclonal anti- } \\
\text { parvalbumin } \\
\text { antibody }\end{array}$ & Immunostar & cat. \#24428 & $\begin{array}{l}\text { IHC dilution: } \\
1: 1,000\end{array}$ \\
\hline Antibody & $\begin{array}{l}\text { goat anti-mouse } \\
\text { Alexa-Fluor } 555\end{array}$ & $\begin{array}{l}\text { ThermoFisher } \\
\text { Scientific }\end{array}$ & cat. \#A-21422 & $\begin{array}{l}\text { IHC dilution: } \\
1: 400\end{array}$ \\
\hline Antibody & $\begin{array}{l}\text { donkey anti- } \\
\text { mouse Alexa- } \\
\text { Fluor } 594\end{array}$ & $\begin{array}{l}\text { ThermoFisher } \\
\text { Scientific }\end{array}$ & cat \#A-32744 & $\begin{array}{l}\text { IHC dilution: } \\
1: 400\end{array}$ \\
\hline Antibody & $\begin{array}{l}\text { goat anti-guinea } \\
\text { pig Alexa-Fluor } \\
488\end{array}$ & $\begin{array}{l}\text { ThermoFisher } \\
\text { Scientific }\end{array}$ & cat \#A-11073 & $\begin{array}{l}\text { IHC dilution: } \\
1: 500\end{array}$ \\
\hline Antibody & $\begin{array}{l}\text { goat anti-rabbit } \\
\text { Alexa-Fluor } 488\end{array}$ & $\begin{array}{l}\text { ThermoFisher } \\
\text { Scientific }\end{array}$ & cat \# A32731 & $\begin{array}{l}\text { IHC dilution: } \\
1: 500\end{array}$ \\
\hline $\begin{array}{l}\text { Chemical } \\
\text { reagent }\end{array}$ & $\begin{array}{l}\text { Vectashield } \\
\text { HardSet Antifade } \\
\text { Mounting Medium } \\
\end{array}$ & $\begin{array}{l}\text { Vector } \\
\text { Laboratories }\end{array}$ & $\begin{array}{l}\text { cat. \#H-1400- } \\
10\end{array}$ & \\
\hline $\begin{array}{l}\text { Chemical } \\
\text { reagent }\end{array}$ & $\begin{array}{l}\text { Protease inhibitor } \\
\text { cocktail }\end{array}$ & $\begin{array}{l}\text { ThermoFisher } \\
\text { Scientific }\end{array}$ & cat. \# 78430 & \\
\hline $\begin{array}{l}\text { Chemical } \\
\text { reagent }\end{array}$ & Laemmeli buffer & Bio-Rad & $\begin{array}{l}\text { cat. \# } \\
1610737 \\
\end{array}$ & \\
\hline $\begin{array}{l}\text { Chemical } \\
\text { reagent }\end{array}$ & Restore buffer & $\begin{array}{l}\text { ThermoFisher } \\
\text { Scientific }\end{array}$ & cat. \#21059 & \\
\hline $\begin{array}{l}\text { Commercial } \\
\text { assay or kit }\end{array}$ & ECL reagent & GE Healthcare & $\begin{array}{l}\text { cat. } \\
\text { \#RPN2232 }\end{array}$ & \\
\hline $\begin{array}{l}\text { Commercial } \\
\text { assay or kit }\end{array}$ & $\begin{array}{l}\text { Bicinchoninic acid } \\
\text { assay }\end{array}$ & $\begin{array}{l}\text { ThermoFisher } \\
\text { Scientific }\end{array}$ & Cat.\# 23225 & \\
\hline Software & Neurolucida 11.03 & $\begin{array}{l}\text { MBF } \\
\text { Bioscience }\end{array}$ & & RRID:SCR_016788 \\
\hline Software & ANY-maze & Stoelting Co. & & $\begin{array}{l}\text { Video tracking } \\
\text { software } \\
\text { RRID:SCR_014289 }\end{array}$ \\
\hline Software & IgorPro 6.36 & $\begin{array}{l}\text { Wavemetrics, } \\
\text { Portland, OR, } \\
\text { USA }\end{array}$ & & RRID:SCR_000325 \\
\hline Software & Prism 7.0 & $\begin{array}{l}\text { GraphPad, San } \\
\text { Diego, CA, } \\
\text { USA }\end{array}$ & & RRID:SCR_002798 \\
\hline
\end{tabular}

Ethics Statement. All animal procedures used in the present study were approved by the Institutional Animal Care and Use Committee of Albany Medical College (ACUP \#18-04002), and strictly conformed to the Guide for the Care and Use of Laboratory Animals as adopted by the U.S. National Institutes of Health (https://grants-nih-gov.elibrary.amc.edu/grants/olaw/Guidefor-the-Care-and-Use-of-Laboratory-Animals.pdf). 
Animals. Mice were housed in a temperature, humidity and light-controlled facility on a $12 \mathrm{~h}$ light/dark cycle and given free access to food and water. Experiments were performed in agematched controls of both sexes, divided as evenly as possible between males and females. Lrrc8a $a^{\mathrm{fl} / \mathrm{fl}}($ Swell/1/flfl) mice were generated as previously described(Zhang et al. 2017). Brainspecific Lrrc8a knockout mice were produced by breeding $L r r c 8 a^{f / / f l}$ female mice with commercially available Nestin ${ }^{\mathrm{Cre} /+}$ male mice (B6.Cg-Tg(Nes-Cre) $1^{\mathrm{KIn}} / \mathrm{J}$; Jackson Laboratory stock \#003771), both on a C57BL/6 background. Nestin ${ }^{\mathrm{Cre} /+} ; \mathrm{LrrC}^{\mathrm{f}} \mathrm{a}^{\mathrm{fl} /+}$ heterozygous males were crossed again with $L r r c 8 a^{\text {fl/fl }}$ female mice to produce Nestin ${ }^{C r e /+} ; L r r C 8 a^{\text {fl/fl }}$ knockout mice and littermate controls. All genotypes were confirmed by PCR analysis across the predicted loxP insertion sites surrounding Lrrc8a exon 3, or for the Nestin ${ }^{\text {Cre }}$ transgene insertion into mouse Chromosome 12 according to the Jackson Laboratory genotyping protocol.

Behavior Testing. To characterize the behavioral phenotype of the brain-specific LRRC8A KO mice, we performed several behavioral assays. These analyses initially included the following four procedures: open field test (OFT), elevated plus maze (EPM), rotarod, and Morris water maze (MWM). Due to animal mortality, only OFT, EPM, and abbreviated MWM tests were performed as described below.

Several cohorts of 6 to 8-wk-old animals of all four genotypes were tested at the same time of day (AM) in conditions of dim-light to facilitate animal activity ( 15 lux). For the OFT test, mice were placed, one at a time, into a quadrant operant chamber containing four identical $50 \times 50 \mathrm{~cm}$ cubes and recorded for $10 \mathrm{~min}$. ANY-maze software (Wood Dale, IL, USA) calculated the percentage of time the animal spent in the center or the periphery of the OFT, as well as the total distance travelled.

The next day, the same animals performed the EPM test. One at a time, mice were placed in the center of the EPM apparatus with two open arms and two closed arms $(32 \mathrm{~cm}$ each), standing $39 \mathrm{~cm}$ above the ground. Their activity was recorded for $5 \mathrm{~min}$, and ANY-maze software was used to determine the entries into, and the amount of time spent in the open or closed arms, as well as total distance travelled.

On the third day, a cohort of animals performed a modified version of the MWM test, aimed at revealing visual deficits. For this test, a large circular tub (diameter of $120 \mathrm{~cm}$ ) was filled with $18-22^{\circ} \mathrm{C}$ water and a plexiglass platform with a large black-and-white flag was placed in the upper-left quadrant so that the platform lay $\sim 1 \mathrm{~cm}$ above the water. Black electrical tape was used to mark four different shapes in each of the four quadrants on the walls of the tank and the room. Mice were placed into the water at the starting location $180^{\circ}$ from the platform and ANY-maze software was used to record the time for each animal to reach the platform. Following the trial, animals were dried off and allowed to warm up for at least 30 minutes. This process was repeated for a total of 5 trials per animal.

Seizure semiology for observed seizures were assessed using the Racine scale(Racine 1972) for clonic seizures and a modified brainstem seizure scale validated in our prior work(Kadiyala et al. 2016).

Primary cell cultures. Primary cultures of mouse astrocytes were prepared from the brain cortices of newborn (P0-P1) animals of both sexes and all four genotypes. Complete litters were utilized, and tail snips of each pup were taken for genotyping by PCR. Each pup's brain tissue was used for an individual cell preparation. Pups were quickly decapitated, and their brains were harvested in ice-cold sterile Dulbecco's Phosphate-Buffered Saline (DPBS) without 
calcium and magnesium (ThermoFisher Scientific, cat. \#14190144). Brain cortices were dissected out and cleared of meninges. Cortical tissue was then minced using a sterile surgical blade, mechanically homogenized by pipetting through a one-mL pipette tip, and further digested for $5 \mathrm{~min}$ at room temperature $\left(22^{\circ} \mathrm{C}\right)$ using a TrypLE Express recombinant protease (ThermoFisher Scientific, cat. \#12605010). The dissociated cells were sedimented by a brief centrifugation ( $900 \mathrm{~g}$ for $10 \mathrm{~min}$ at $4^{\circ} \mathrm{C}$ ). Pellets were resuspended in Earl's minimal essential medium (MEM) supplemented with 10\% heat inactivated horse serum (HIHS) and $50 \mathrm{U} / \mathrm{mL}$ penicillin/streptomycin (P/S; all components from ThermoFisher Scientific/Invitrogen, Carlsbad, CA, USA). Cells from each pup brain were plated onto an individual T75 flask pre-treated with poly-D-lysine (Sigma-Millipore, cat. \#P6407), to obtain a purified astrocyte population. The cultured astrocytes were grown for at least 10 days and maintained for up to four weeks at $37^{\circ} \mathrm{C}$ in a humidified atmosphere containing $5 \% \mathrm{CO}_{2} /$ balance air. The purity of cell cultures was routinely confirmed using immunocytochemistry with the astrocyte marker, glial fibrillary acidic protein (GFAP, Millipore-Sigma, cat. \#G5163).

Processing of tissue samples. For tissue collection, mice were euthanized with a lethal injection of sodium pentobarbital and perfused transcardially with room temperature PBS. This was followed by either perfusion with ice-cold PBS for western blot and amino acid analyses, or 4\% paraformaldehyde in PBS for immunohistochemistry.

For western blotting, brain, heart, kidney, lung, and liver were removed and immediately snap-frozen in liquid nitrogen. Prior to assaying, frozen tissues were homogenized using a mechanical homogenizer (PRO Scientific, Oxford, CT, USA, cat. \# PRO200) in a tissue lysis buffer containing $150 \mathrm{mM} \mathrm{NaCl}, 50 \mathrm{mM}$ Tris $\mathrm{HCl}(\mathrm{pH} 8), 0.1 \%$ Triton X-100 and $5 \%$ protease inhibitor cocktail (ThermoFisher Scientific, cat. \# 78430). Samples were clarified by a brief centrifugation $\left(10,000 \mathrm{~g}\right.$ for $5 \mathrm{~min}$ at $\left.4^{\circ} \mathrm{C}\right)$ and the supernatants were collected and diluted with $2 \times$ reducing Laemmeli buffer (Bio-Rad, Hercules, CA, USA, cat. \# 1610737). For preparation of cell lysates, confluent $60-\mathrm{mm}$ Petri dishes were washed from cell culture media with a Basal medium (for composition see below) and lysed in $2 \%$ SDS plus 8 mM EDTA and diluted with $4 \times$ reducing Laemmeli buffer.

For immunohistochemistry, brains were removed and post-fixed in $4 \%$ paraformaldehyde for $24 \mathrm{~h}, 15 \%$ sucrose solution for $24 \mathrm{~h}$, and $30 \%$ sucrose solution for full cryopreservation (all steps at $4^{\circ} \mathrm{C}$ ). Brains were further mounted on a cryostat specimen stage using Tissue-Tek O.C.T. compound (Sakura Finetek, Torrance, CA, USA), frozen to $-20^{\circ} \mathrm{C}$ and sectioned using a CM3050 cryostat (Leica, Wetzlar, Germany) into 25- $\mu$ m thick sections. Sections were collected into cryoprotectant media containing $30 \%$ ethylene glycol and $20 \%$ glycerol in Tris buffered saline (TBS) and stored at $-20^{\circ} \mathrm{C}$ until morphological or immunohistochemical staining assays were conducted.

Western blot analyses. Protein expression levels were measured in lysates prepared from whole brain, samples of other organs, or from primary astrocyte cultures. Protein samples in reducing Laemmeli buffer were boiled for $5 \mathrm{~min}$ (except for VGAT analysis), loaded onto 10\% Mini-PROTEAN TXG gels (Bio-Rad, cat \#4561033), and separated according to a standard SDS-PAGE procedure. Separated proteins were electrotransferred onto a polyvinylidene fluoride membrane (PVDF, Bio-Rad, cat. \#1620177). Membranes were blocked for 5 min in Tris-buffered saline containing $0.1 \%$ Tween-20 (TBS-T) and $5 \%$ milk. They were further incubated overnight in the same blocking buffer with one of the following primary antibodies: mouse monoclonal anti-LRRC8A (Santa Cruz, cat. \#sc-517113, dilution 1:500), rabbit polyclonal 
anti-GAD65/67 (Millipore-Sigma, G5163, 1:2,000), rabbit polyclonal anti-VGAT (Invitrogen, cat. \#Pa5-27569, 1:1000), or rabbit polyclonal anti-glutamine synthetase (Millipore-Sigma, cat. \#G2781, 1:20,000). Blots were washed with TBS-T and probed with the species-matched secondary horseradish peroxidase-conjugated antibody: donkey anti-rabbit (GE Healthcare, cat. \#NA932, dilution 1:10,000), or sheep anti-mouse IgG (GE Healthcare, cat \#NA931, 1:10,000) in TBS-T containing $5 \%$ milk for $2 \mathrm{~h}$ at room temperature. After a final wash, immunoreactivity was measured using ECL reagent (GE Healthcare, cat. \#RPN2232) and visualized in a Bio-Rad Gel Doc Imager. For loading controls, membranes were either washed overnight in TBS-T or stripped with Restore buffer (ThermoFisher Scientific, cat. \#21059), re-probed with the HRPconjugated primary anti- $\beta$-actin antibody for 20 min (Millipore-Sigma, cat. \#A-3854, 1: 50,000), and the immunoreactivity was visualized as described above. No $\beta$-actin immunoreactivity was found in heart tissue lysates, so these blots were re-probed with anti-GAPDH antibody (Millipore-Sigma, cat \#G9545, 1:10000) for $1 \mathrm{hr}$ at RT. Protein expression levels were semiquantitively determined by measuring band intensity using ImageJ software(Schneider et al. 2012) and further normalization to the $\beta$-actin or GAPDH signal from the same membrane.

Neuroanatomical analysis and immunohistochemistry. To analyze brain morphology, brain sections were stained with thionin. Frozen sections were washed from cryoprotectant media with PBS, mounted on charged slides, and dried overnight. The tissue was progressively rehydrated by dipping into $100 \%, 95 \%, 70 \%$, and $50 \%$ ethanol, followed by a 15 -sec thionin staining $(0.25 \%$ thionin, $1 \mathrm{M}$ sodium acetate and $1 \mathrm{M}$ glacial acetic acid, $\mathrm{pH} 4.3)$. Slides were washed in water and then progressively dehydrated again through the same ethanol solutions before being cleared with Xylene and mounted with Permount (ThermoFisher Scientific).

For immunohistochemical detection of cell-specific markers, floating sections were washed from cryoprotectant with PBS and blocked for $1 \mathrm{~h}$ at room temperature with either 3\% normal goat serum (NGS) plus 0.3\% Triton X-100 (TX-100) in PBS for staining myelin basic protein (MBP), or $2 \%$ NGS and $0.2 \%$ TX-100 for detecting NeuN, GFAP, and parvalbumin immunoreactivity. Floating sections were next incubated overnight at $4^{\circ} \mathrm{C}$ with one or two primary antibodies in blocking buffer with the following dilutions: rabbit polyclonal antiRBFOX3/NeuN (Novus Biologicals, cat. \#NBP1-77686, 1:200), mouse monoclonal anti-GFAP (Millipore-Sigma, cat. \#G5163, 1:400), mouse monoclonal anti-MBP antibody (Biolegend, cat. \#SMI-99P, 1:1000), or guinea pig polyclonal anti-parvalbumin antibody (Immunostar, cat. \#24428, 1:1000). Sections were washed in PBS, and then incubated for $2 \mathrm{~h}$ at room temperature with one of the species-matching conjugated secondary antibodies (all from ThermoFisher Scientific): goat anti-mouse Alexa-Fluor 555 (cat. \#A-21422, 1:400 for MBP staining), donkey anti-mouse Alexa-Fluor 594 (cat \#A-32744, 1:400 for GFAP), goat anti-guinea pig Alexa-Fluor 488 (cat \#A-11073, 1:500 for parvalbumin), or goat anti-rabbit Alexa-Fluor 488 (cat \# A32731, 1:400 for NeuN). Sections were washed from secondary antibody with PBS, counterstained with $0.05 \mu \mathrm{g} / \mathrm{mL}$ DAPI at room temperature for 5 minutes, and further washed with PBS. They were mounted on charged slides, dried in the dark overnight at room temperature, and mounted with Vectashield HardSet Antifade Mounting Medium (Vector Laboratories, cat. \#H-1400-10).

NeuN-positive cells were quantified in the predefined $\sim 2.1 \mathrm{~mm}^{2}$ region of cortex situated above hippocampus in sagittal brain sections between +1.7 and $+1.9 \mathrm{~mm}$ AP from bregma. GFAP-positive cells were counted in the same sections in the entire hippocampus, with an average volume of $2.6 \mathrm{~mm}^{2}$. We additionally the GFAP signal intensity was additionally 
quantified in a $\sim 1.6 \mathrm{~mm}^{2}(500 \times 500$-pixel) region of the hippocampus encompassing the CA1 region. MBP immunoreactivity was analyzed as the thickness and length of corpus callosum in brain sections from +0.38 to $+0.98 \mathrm{~mm}$ AP from bregma. We further quantified the MBP signal intensity in several representative $\sim 0.2 \mathrm{~mm}^{2}$ ( $50 \times 50$ pixel) regions of the corpus callosum, cortex, and striatum. Parvalbumin-positive interneurons were counted in the pyramidal cell layer of the CA1 hippocampal region, or a $\sim 2.4 \mathrm{~mm}^{2}$ region of the cortex from the midline to a vertical marker at the turn of the hippocampus, in sections between +1.7 and $+1.9 \mathrm{~mm}$ AP from bregma.

Thionin-stained and immunolabeled brain sections were scanned using a Zeiss AX10 microscope at $250 \times$ magnification, and the resulting images stitched together with Neurolucida 11.03 software (MBF Bioscience, Williston, VT, USA). Cell numbers and the intensity of immunoreactive signal were quantified using ImageJ threshold analysis or manual cell counting as specified in the Results section. In all cases, the person who performed analysis was blinded to animal genotype.

VRAC activity assay. Functional activity of the volume-regulated channel was evaluated by measuring the swelling-activated release of the non-metabolizable analog of glutamate, D$\left[{ }^{3} \mathrm{H}\right]$ aspartate, as previously described(Abdullaev et al. 2006; Schober et al. 2017). Two-tothree-week old primary astrocyte cultures from all four genotypes were re-plated onto $18 \times 18$ $\mathrm{mm}$ glass coverslips treated with poly-D-lysine, grown to $80-90 \%$ confluency, and loaded overnight with MEM + HIHS cell culture media supplemented with $4 \mu \mathrm{Ci} / \mathrm{mL} \mathrm{D}-\left[{ }^{3} \mathrm{H}\right]$ aspartate. Coverslips were washed in isosmotic Basal medium (in $\mathrm{mM}$ ) $135 \mathrm{NaCl}, 3.8 \mathrm{KCl}, 1.2 \mathrm{MgSO}_{4}, 1.3$ $\mathrm{CaCl}_{2}, 1.2 \mathrm{KH}_{2} \mathrm{PO}_{4}, 10 \mathrm{HEPES}, 10$ D-glucose ( $\mathrm{pH} 7.4$, osmolarity $290 \pm 2 \mathrm{mOsm}$ ) and placed in a custom-made Leucite perfusion chamber with inlet/outlet ports and $\sim 200 \mu \mathrm{m}$ of space between the cells and the Teflon screw-top. Swelling was induced by perfusing cells with medium in which osmolarity was decreased to $200 \pm 2$ mOsm (50 mM reduction in [NaCl]). Coverslips were superfused with either isosmotic or hypoosmotic media at a rate of $\sim 1.2$ $\mathrm{mL} / \mathrm{min}$. One-minute perfusate fractions were collected into scintillation vials using an automated fraction collector Spectra/Chrom CF-1 (Spectrum Chemical, New Brunswick, NJ, USA). After the last minute of collection, total cell lysates were collected from coverslips using $2 \%$ sodium dodecyl sulfate (SDS) plus $8 \mathrm{mM}$ EDTA lysis buffer. Samples were mixed with an Ecoscint A scintillation liquid (Atlanta Biologicals, Atlanta, GA, USA, cat. \#LS-273), and [ $\left.{ }^{3} \mathrm{H}\right]$ content was measured offline in a TriCarb 2900 scintillation counter (Perkin Elmer, Waltham, MA). Results are reported as fractional release rates relative to the total $\left[{ }^{3} \mathrm{H}\right]$ content at each time-point, using an Excel-based custom program.

Electrophysiology. Coronal slices were prepared from the hippocampi of 5-7-week-old mice of both sexes. The two genotypes, $L r r c 8 a^{\mathrm{fl} /+}(\mathrm{fl}+)$ and $L r r c 8 a^{\mathrm{f} / \mathrm{fl} l}(\mathrm{fl} / \mathrm{fl})$, were used as a combined control and compared to LRRC8A KO animals (Nestin ${ }^{\mathrm{Cre} /+} ; \mathrm{LrrC}^{\mathrm{ff}} \mathrm{a}^{\mathrm{flfl}}$ ). Mice were deeply anesthetized with isoflurane and intracardially perfused with ice cold Recovery Medium of the following composition (in $\mathrm{mM}$ ): $119 \mathrm{NaCl}, 2.5 \mathrm{KCl}, 0.5 \mathrm{CaCl}_{2}, 1.3 \mathrm{MgSO}_{4} \cdot \mathrm{H}_{2} \mathrm{O}, 4 \mathrm{MgCl}_{2}, 26.2$ $\mathrm{NaHCO}_{3}, 1 \mathrm{NaH}_{2} \mathrm{PO}_{4}$, and $22 \mathrm{D}$-glucose (320 mOsm, pH7.4, pre-equilibrated with $95 \% \mathrm{O}_{2} / 5 \%$ $\mathrm{CO}_{2}$ ). The brain was rapidly removed and placed in ice-cold Slicing Solution containing (in $\mathrm{mM}$ ): 227 sucrose, $2.5 \mathrm{KCl}, 2 \mathrm{MgSO}_{4}, 1 \mathrm{CaCl}_{2}, 1.2 \mathrm{NaH}_{2} \mathrm{PO}_{4}, 26 \mathrm{mM} \mathrm{NaHCO}_{3}, 22$ D-glucose (320mOsm, pH 7.4, constantly bubbled with $95 \% \mathrm{O}_{2} / 5 \% \mathrm{CO}_{2}$ ). The $250-\mu \mathrm{m}$ thick slices were prepared using a vibrating blade microtome (VT1200S; Leica Microsystems). Once cut, the 
slices were transferred into Recovery Medium and incubated in a submersion chamber at $36^{\circ} \mathrm{C}$ for $30 \mathrm{~min}$, and then stored in the same medium at room temperature for up to $5 \mathrm{~h}$.

Unless otherwise stated, the Recording Solution contained (in $\mathrm{mM}$ ): $119 \mathrm{NaCl}, 2.5 \mathrm{KCl}$, $1.2 \mathrm{CaCl}_{2}, 1 \mathrm{MgCl}_{2}, 26.2 \mathrm{NaHCO}_{3}, 1 \mathrm{NaH}_{2} \mathrm{PO}_{4}, 22$ glucose ( $\left.\mathrm{pH} 7.4\right)$. The same Recording Solution was used to fill the glass capillaries used for extracellular field recordings. Stimulating and recording electrodes were both placed in the middle third of the hippocampal stratum radiatum, $\sim 100 \mu \mathrm{m}$ away from each other. Postsynaptic responses were evoked by delivering constant voltage electrical pulses $(50 \mu \mathrm{s})$ through a stimulating bipolar stainless-steel electrode (Frederick Haer, Bowdoin, ME, USA, catalog \#MX21AES(JD3)). The resistance of the recording electrode was $\sim 1.5 \mathrm{MOhm}$. Whole-cell patch-clamp recordings in voltage-clamp mode were obtained from CA1 pyramidal cells using a pipette solution containing (in $\mathrm{mM}$ ): 120 $\mathrm{CsCH}_{3} \mathrm{SO}_{3}, 10$ EGTA, 2 MgATP, 0.2 NaGTP, 5 QX-314Br, 20 HEPES (290 mOsm, pH 7.2). Current clamp recordings were obtained by replacing $\mathrm{CsCH}_{3} \mathrm{SO}_{3}$ in the internal solution with equimolar $\mathrm{KCH}_{3} \mathrm{SO}_{3}$ (QX-314 was omitted). Data were discarded if the series resistance changed $>20 \%$ during the course of the experiment. All recordings were obtained using a Multiclamp 700B amplifier and filtered at $10 \mathrm{kHz}$ (Molecular Devices, San Jose, CA, USA), converted with an 18-bit $200 \mathrm{kHz}$ A/D board (HEKA, Holliston, MA, USA), digitized at $10 \mathrm{kHz}$, and analyzed offline with custom-made software (A.S.) written in IgorPro 6.36 (Wavemetrics, Portland, OR, USA). All recordings were performed at room temperature.

Inhibitory postsynaptic currents (IPSCs) were further explored in whole-cell mode using a multiple-probability fluctuation analysis (MPFA). MPFA provides a method for estimating the quantal parameters $N$ and $Q$ from the IPSC variance and mean, under a range of release probability conditions, which were obtained by changing the extracellular concentration of calcium(Silver et al. 1998; Clements and Silver 2000; Silver 2003). Variance and mean current at the peak of the IPSC were normalized to the values measured at $\left[\mathrm{Ca}^{2+}\right]_{0}=0.5 \mathrm{mM}$. The resulting data were fit parabolically using the equation $F(I)=Q I-\frac{I^{2}}{N}$.

HPLC analysis of brain amino acid content. Whole-brain tissue lysates were prepared from snap-frozen tissue by homogenizing one hemisphere in $0.4 \mathrm{M}$ perchloric acid. The tissue homogenates were clarified by centrifugation (10,000 g for $10 \mathrm{~min})$. Pellets were saved to determine total protein content and the supernatants were used to determine tissue amino acid levels by reverse-phase high pressure liquid chromatography (HPLC) as previously described(Dohare et al. 2014). An Agilent 1200 HPLC setup and Eclipse XDB-C18 column (both from Agilent Technologies, Santa Clara CA, USA) were used for HPLC analysis. Each sample was subjected to a precolumn derivatization with a freshly prepared mix of ophthalaldehyde and 2-mercaptoethanol in $0.4 \mathrm{M}$ sodium tetraborate buffer $(\mathrm{pH}=9.5)$ and were eluted with a solvent containing $30 \mathrm{mM} \mathrm{NaH}_{2} \mathrm{PO}_{4}, 1 \%$ tetrahydrofuran, $30 \mathrm{mM}$ sodium acetate, $0.05 \%$ sodium azide, and increasing concentrations of HPLC grade methanol (10-30\%). A programmable 1200 series fluorescence detector (Agilent, Santa Clara, CA, USA) was used to measure the fluorescence signal from each sample. The identification of peaks and concentrations of individual amino acids in the samples were determined by processing amino acid standards of L-alanine, L-aspartate, L-glutamate, taurine, L-glutamine, and GABA. All data were normalized to the total protein content determined in protein pellets after neutralization with $10 \mathrm{~N} \mathrm{NaOH}$ and sonication in 2\% SDS plus 8 mM EDTA using a bicinchoninic acid assay (ThermoFisher Scientific) and bovine serum albumin as a standard. 
Statistics. All data are presented as the mean values \pm SEM, with the number of independent experiments $(n)$ indicated in each figure. For all experiments, $n$ represents an individual animal as a biological replicate, unless otherwise stated. In radiotracer efflux assays, $n$ represents an individual coverslip (9-12), however all relevant experiments were performed using cells from at least three different cell cultures prepared from different animals. In immunohistochemistry analyses cell counts and fluorescence intensities from immunohistochemical images were recorded separately from both hemispheres, because we observed differences in bilateral regions in some animals.

Experimental group numbers were pre-planned prior to the initiation of experiments, with 10 animals per group for behavioral assays, 5 animals per group for western blot analyses, and 6 animals per group for all immunohistochemical and biochemical assays. These group numbers were selected empirically, based on variability seen in our previous studies. Due to the novel nature of this work, specific sample size calculations were done for some but not all experiments. Generally, we planned to be able to detect a difference of $25 \%$ between groups with a power of 0.8 and an $\alpha$ of 0.05 . In all experiments, animals and samples were coded and analysis was done by a blinded experimenter. A small number of experimental values were excluded from analysis but only for the following reasons: (a) the data point in OFT behavioral assay (fl/fl behavioral timepoint) was more than 2 SD away from the mean, (b) few aberrant values in VRAC activity assays were due to broken coverslip and disrupted perfusion, and (c) in $\mathrm{IHC}$ experiments the cell number or fluorescence intensively values could not be reliably calculated on one side of the brain due to damaged tissue. These data have been included in the primary data files for each figure, with the appropriate labels designating their exclusion from analysis.

Statistical differences between groups were determined by one-way ANOVA with Bonferroni post hoc correction for multiple comparisons. In cases where data were not normally distributed, the Kruskal-Wallis test was performed with Dunn's post hoc correction for multiple comparisons. Normalized data were analyzed using a Student's one-sample t-test, where all mean values are compared to 1 . For these data, Bonferroni correction was performed according to the formula: $p=1-(1-p)^{n}$, where $p$ is the un-adjusted $p$-value and $n$ is the number of comparisons. For all figures, ${ }^{*} p<0.05,{ }^{* *} p<0.01,{ }^{* * *} p<0.001$, or are not significant unless otherwise noted. All statistical analyses and figures were prepared using Prism 7.0 (GraphPad, San Diego, CA, USA).

\section{Acknowledgements}

We thank Drs. Yannick Poitelon, Sophie Belin, Damian S. Shin, Ashley Kopec, Yunfei Huang, Joseph E. Mazurkiewicz, Matthew Shapiro, and Ms. Linda Barenboim for methodological advice on various aspects of this work. We are grateful to Ms. Julia Nalwalk for help with this study and critical suggestions on the manuscript. 


\section{Additional information}

\section{Funding}

\begin{tabular}{lll} 
Funder & Grant reference number & Author \\
\hline National Institute of Health & R01 NS111943 & Alexander A. Mongin \\
\hline National Institute of Health & R01 NS092062 & Russell J. Ferland \\
\hline National Institute of Health & F31 NS111889 & Corinne S. Wilson \\
\hline National Science Foundation & 1655365 & Annalisa Scimemi \\
\hline
\end{tabular}

\section{Author contributions}

CSW and AAM conceived the study. CSW, PD, AS and AAM developed and finalized experimental design. CSW, PD, SO, and AS performed experiments and analyzed the data. RJF, RS, AS, and AAM provided conceptual analysis and analytical tools. CSW, PD, AS, and AAM have written the manuscript. All authors contributed to the final manuscript edits.

Preprint information: This manuscript has been deposited to bioRxiv in a preprint form under the Creative Commons license (CC-BY-NC-ND). doi: 10.1101/2020.05.22.109462

\section{Additional files}

\section{Supplementary files}

- Transparent reporting form

- Primary data file

- Statistical values tables

- Media files of seizures in bLRRC8A KO mice

\section{Data availability}

All primary data used this work and complete statistical analyses for each figure are provided in the supplements and have been deposited to the Open Science Framework (accession number https://osf.io/nyzwx/registrations [registered on 2020/05/22]). Complete set of full-length western blot images, representative full-size immunohistochemistry images, and representative video recordings of mice with seizures are included in Supplemental Information and available from the Open Science Framework. 
Fig. 1. Initial characterization of animals with the brain-specific deletion of the LRRC8A protein. A, Breeding strategy and the genotype distribution for the tissue-specific deletion of LRRC8A in the brain using Nestin Cre-targeted excision of Lrrc8 ${ }^{\mathrm{fl} / \mathrm{fl}}$. Dotted line denotes expected Mendelian ratio for all genotypes; numbers indicate the total number of animals of each genotype. B, Western blot analysis of LRRC8A protein levels in whole-brain lysates, double-normalized to $\beta$-actin and $\mathrm{fl} /+$ controls. Data are the mean values \pm SEM from 5 different animals per group. ${ }^{* *} p<0.001$, one-sample t-test with Bonferroni correction. Lower inset shows representative western blot images for LRRC8A and $\beta$-actin re-probed on the same membrane. C, VRAC activity in primary astrocyte cultures, measured as swelling-activated $D-\left[{ }^{3} \mathrm{H}\right]$ aspartate release in response to hypoosmotic medium. Data are the mean values \pm SEM of 9 independent experiments per genotype in three different astrocyte cultures. ${ }^{* *} p<0.01$, maximal release rate, LRRC8A KO vs. fl/fl, ${ }^{* * *} \mathrm{p}<0.001$, LRRC8A KO vs fl/+ and Het. ${ }^{\# \#} \mathrm{p}<0.001$, integral (10-min) release values LRRC8A KO vs. all other groups. ANOVA with Bonferroni correction. D, Representative thionin-stained brain slices used for neuroanatomical analysis ( $n=6$ per genotype). E, Representative eight-week old male mice of each genotype. $\mathbf{F}$, Body weight in male (solid symbols) and female (open symbols) animals of all four genotypes at 8 weeks. G, Kaplan-Meier survival curve of animals with the brain deletion of LRRC8A and their littermates. The curve is censored for animals euthanized for tissue analyses. ${ }^{* * *} p<0.001$, Log-rank (Mantel-Cox) test.

Source data: Primary data file.

Figure supplement 1.1: Full-length western blots for LRRC8A protein and $\beta$-actin probed in whole-brain tissue lysates from $\operatorname{Lrc8} a^{\mathrm{fl} / \mathrm{fl}}(\mathrm{fl} / \mathrm{fl}), \operatorname{LrrCB}^{\mathrm{fl} /++}(\mathrm{fl} /++), N e s t i n^{\mathrm{Cre} /+} ; \operatorname{LrrCB}^{\mathrm{fl} /++}$ (Het), or Nestin ${ }^{\mathrm{Cre} /+} ;$ LrrC8a $^{\mathrm{fl} / f l}(\mathrm{KO})$ mice.

Figure supplement 1.2: Quantitative analysis and full-length western blots for LRRC8A protein and $\beta$-actin (or GAPDH) probed in the liver, kidney, lung and heart tissue lysates from Lrrc8a ${ }^{\mathrm{fl} / f \mathrm{l}}$

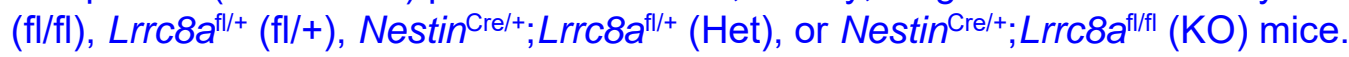

Figure supplement 1.3: Quantitative analysis and full-length western blot images for LRRC8A protein and $\beta$-actin probed in primary astrocyte culture lysates, prepared from $L \mathrm{rrc} 8 \mathrm{a}^{\mathrm{fl} / \mathrm{fl}}(\mathrm{fl} / \mathrm{fl})$,

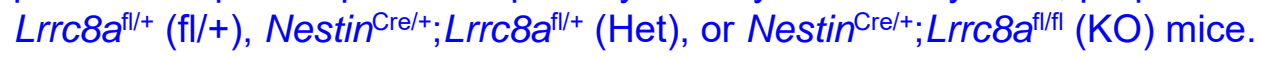

Figure supplement 1.4: Representative full sets of thionin-stained brains ( 5 animals per

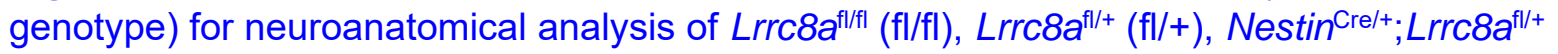
(Het), or Nestin ${ }^{\mathrm{Cre} /+} ;$ LrrC8a $^{\text {fl/fl }}(\mathrm{KO})$ mice.

Figure supplement 1.5: Body weights of male and female animals at 6 and 8 weeks of age.

Fig. 2. Immunohistochemical analyses of the brain cell populations targeted by the Nestin $^{\text {Cre }}$ promoter. A, Representative images of the immunoreactivity for the neuronal marker NeuN (green) and DAPI (blue) in LrrC8a ${ }^{\mathrm{fl} /+}$ controls (fl/+, A1) and Nestin ${ }^{\mathrm{Cre} /+} ; \mathrm{LrrC}^{\mathrm{fl} / / \mathrm{fl}}$ knockouts $(\mathrm{KO}, \mathrm{A} 2)$ brains. Insets in $\mathrm{A} 3$ are the higher magnification images of NeuN signal in cortex and hippocampus. A4, Quantification of $\mathrm{NeuN+}$ cell numbers in the cortical region outlined in A3. 
Data are the mean values \pm SEM from 6 animals per group, counted bilaterally. B, Typical images and quantification of the astroglial marker GFAP (red) in hippocampal areas of $L r r c 8 a^{\mathrm{fl} /+}$ controls $(\mathrm{fl} /+, \mathrm{A} 1)$ and $\mathrm{Nestin} \mathrm{Cre} /+_{;} \mathrm{LrrC}_{\mathrm{ra}} \mathrm{a}^{\mathrm{fl} / \mathrm{fl}}(\mathrm{KO}, \mathrm{B} 2)$ animals. Insets show high magnification images (captured at 400x) in hippocampus. B3-B4, Quantification of GFAP+ cell numbers (B3) and the relative GFAP immunofluorescence intensity (B4) in hippocampi of four genotypes. Data are the mean values \pm SEM of 6 animals per group, analyzed by one-way ANOVA with Bonferroni correction (B3) or one-sample t-test (B4). ${ }^{* *} p<0.01$, normalized KO intensity vs. all other genotypes. C, Representative immunoreactivity and quantification of the oligodendroglial marker, myelin basic protein (MBP, red) and DAPI (blue) in $L r r c 8 a^{\mathrm{fl} /+}$ controls (fl/,$+ \mathrm{C} 1$ ) and Nestin ${ }^{\mathrm{Cre} /+}$; LrrC8a $^{\text {fl/fl }}(\mathrm{KO}, \mathrm{C} 2)$ brains. C3-C4, Quantification of corpus callosum thickness (C3) and length (C4) in four genotypes. Data are the mean values \pm SEM of 6 animals per group, measuring medial corpus callosum thickness and individual left and right lengths, analyzed by Kruskal-Wallis with Dunn's multiple comparison test.

Source data: Primary data file.

Figure supplement 2.1: Representative immunohistochemistry images from all four genotypes, stained for the neuronal marker, NeuN, the astroglial marker glial fibrillary acidic protein (GFAP), and the oligodendroglial marker, myelin basic protein (MBP).

Fig. 3. Impact of the brain-specific LRRC8A deletion on animal behavior. A, Representative heat map for control $L r r C 8 a^{f / /+}$ controls and Nestin ${ }^{\mathrm{Cre} /+} ; \mathrm{LrrC} \mathrm{a}^{\mathrm{fl} / \mathrm{fl}}$ knockout mice in the open field test. Color heat map indicates the amount of time spent in the center or periphery of the operant chamber. B, Percentage of the total time that the animals of for genotypes spent in the center of the open field. Data are the mean values \pm SEM of $9 \mathrm{fl} /+$ mice and 10 mice in other groups, analyzed by one-way ANOVA with Bonferroni correction. ${ }^{* *} \mathrm{p}<0.01$, fl/+ vs. $\mathrm{fl} / \mathrm{fl} ;{ }^{* * *} \mathrm{p}<$ $0.001, \mathrm{fl} /+\mathrm{vs}$. KO and Het vs. KO. C, Total distance traveled during the open field test. Data are mean values \pm SEM of $9 \mathrm{fl} /+$ mice and 10 mice in other groups analyzed by one-way ANOVA with Bonferroni correction. ${ }^{*} \mathrm{p}<0.05$, Het vs. KO. D, Representative heat maps for $\mathrm{fl} /+$ control and LRRC8A KO mice in the elevated plus maze with two open and two closed arms. $\mathbf{E}$, Number of entries into the open arm of the elevated plus maze. Data are the mean values \pm SEM of $9 \mathrm{fl} /+$ mice and 10 mice in other groups. F, Distance traveled during the elevated plus maze trial in the same animals as in $\mathrm{E}$.

Source data: Primary data file.

Figure supplement 3.1: Extended behavioral analysis of possible sexual dimorphism in behavioral tests performed in LRRC8A KO mice and their littermate controls.

Figure supplement 3.2: Additional behavioral assays testing visual acuity in LRRC8A $\mathrm{KO}$ transgenic mice.

Fig. 4. Characterization of neuronal excitability in hippocampal slices of LRRC8A KO mice. A, Schematic of whole-cell recordings used to measure the passive and active membrane properties of CA1 pyramidal cells (PCs) in panels B-F. B, Average membrane resistance (B1), resting membrane potential (B2), and holding currents needed to maintain CA1PCs at $-70 \mathrm{mV}(\mathrm{B} 3)$ in 9 control cells (pooled $L r r c 8 a^{\mathrm{fl} /+}[\mathrm{fl} /+]$ and $L r r c 8 a^{\mathrm{fl} / \mathrm{fl}}[\mathrm{fl} / \mathrm{fl}]$ ) vs. $13 \mathrm{LRRC} 8 \mathrm{~A}-$ 
null (KO) cells. C, Representative action potentials recorded from CA1-PCs in response to $5 \mathrm{~ms}$ somatic current step injections of increasing amplitude. D, The average rheobase (D1), action potential threshold (D2), and action potential peak (D3) in control (fl/+ and fl/fl, $\mathrm{n=11}$ ) vs. KO cells $(n=13)$. E, Representative voltage recordings in response to $500-\mathrm{ms}$ positive and negative current step injections in CA1-PCs. F, f/l plots showing the firing rates evoked by somatic current step injections of different amplitudes. Raw data for control slices are shown in grey. Raw data for $\mathrm{KO}$ are in pink. The symbols represent the average of all data collected from control (black, $n=12)$ and KO CA1-PCs (red, $n=13)(F 1)$. F2 shows the sigmoidal fits of the data in F1. G, Schematic of stimulation and extracellular field recordings used to measure the fPSP slope and FV amplitude in panels $\mathrm{H}-\mathrm{I}$. H, Representative recordings (left panels) from fl/+ control and KO slices. Each trace is the average of 20 consecutive recordings. The bar graph on the right) shows the mean normalized values from control $(n=11)$ and KO slices $(n=16)$. I, Representative traces (left panels) and normalized changes (right) in the field recordings in

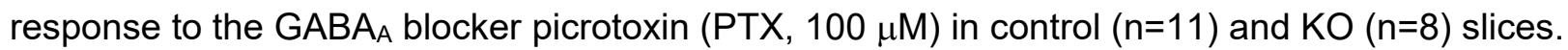
$P$ values indicate differences between PTX vs. no-PTX recordings in the same slices. J, Schematic of whole-cell recordings used to measure the calcium dependence of IPSC amplitude in CA1-PCs, in panels K-L. K, Representative IPSCs (left) recorded at different extracellular calcium concentrations in control and $\mathrm{KO}$ slices. The graph on the right displays the relationship between $\left[\mathrm{Ca}^{2+}\right]_{0}$ and the IPSC amplitude, normalized to its value at $\left[\mathrm{Ca}^{2+}\right]_{0}=0.5$ $\mathrm{mM}$ in control (fl/+) and $\mathrm{KO}$ slices. L, The experimentally measured relationship between variance and mean current at the peak of the IPSC. Both values were normalized to the variance and mean values at $\left[\mathrm{Ca}^{2+}\right]_{0}=0.5 \mathrm{mM}$. The solid curves are the parabolic fit of the data (see Methods). Data reported in this panel represent means $\pm S$.D. Data included in all other panels are means \pm S.E.M.

Source data: Primary data file.

Fig. 5. LRRC8A deletion does not impact the whole-brain protein levels of GAD65/67 and VGAT or numbers of parvalbumin-positive (PV+) interneurons in the hippocampus and cortex. A, The schematic of GABA synthesis and packaging in GABAergic cells. B, Western blot analysis of GAD65/67 protein levels in the whole-brain lysates. C, Western blot analysis of VGAT protein levels in the whole-brain lysates. In $B$ and $C$, the data are the mean values $\pm S E M$ of immunoreactivity in 5 brain lysates per group, double normalized to $\beta$-actin and $\mathrm{fl} /+$ control. Lower insets show representative western blot images for GAD 65/67, VGAT, and matching $\beta$ actin loading controls on the same membrane. D, Representative immunohistochemistry images of parvalbumin (green) and DAPI (blue) staining in brain slices in Lrrc8a ${ }^{\mathrm{fl} /+}$ controls (fl/+, D1) and Nestin ${ }^{\mathrm{Cre} /+} ; \mathrm{LrrC}^{\mathrm{fl} / \mathrm{fl}}(\mathrm{KO}, \mathrm{D} 2)$ brains. D3, Number of PV+ cells in medial cortex. Data are the mean values \pm SEM of 6 animals per genotype, quantified bilaterally. $E$, Magnified images and quantification of the PV+ signal in the hippocampal regions outlined by yellow box in D1 and D2, respectively. E3, Number of PV+ cells in CA1 pyramidal layer. Data are the mean values \pm SEM of 6 animals per genotype, quantified bilaterally.

Source data: Primary data file.

Figure supplement 5.1: Full-length western blot images for GAD65/67 protein and $\beta$-actin immunoreactivity probed in whole-brain tissue lysates from $L r r c 8 a^{\mathrm{fl} / f l}(\mathrm{fl} / \mathrm{fl}), L r r c 8 a^{\mathrm{fl} /+}(\mathrm{fl} /+)$, Nestin ${ }^{\mathrm{Cre} /+} ; \mathrm{LrrCB}^{\mathrm{fl} /+}$ (Het), or Nestin ${ }^{\mathrm{Cre} /+} ;$ LrrC8a $^{\mathrm{fl} / \mathrm{fl}}(\mathrm{KO})$ mice. 
Figure supplement 5.2: Full-length western blot images for VGAT protein and $\beta$-actin immunoreactivity probed in whole-brain tissue lysates from $\operatorname{Lrc8} a^{\mathrm{fl} / \mathrm{fl}}(\mathrm{fl} / \mathrm{fl}), \operatorname{Lrc} 8 \mathrm{a}^{\mathrm{fl} /+}(\mathrm{fl} /++)$, Nestin ${ }^{\mathrm{Cre} /+} ;$ LrrC8a $^{\mathrm{fl} /++}$ (Het), or Nestin ${ }_{\mathrm{Cre} /+} ; \operatorname{LrrCB}^{\mathrm{fl} / \mathrm{fl}}(\mathrm{KO})$ mice.

Figure supplement 5.3: Representative full set of images illustrating parvalbumin immunoreactivity in brain sections prepared from 8-week-old $L r r c 8 a^{\mathrm{fl} / \mathrm{fl}}(\mathrm{fl} / \mathrm{fl}), L \mathrm{rrc} 8 \mathrm{a}^{\mathrm{fl} /+}(\mathrm{fl} /+)$, Nestin ${ }^{\mathrm{Cre} /+} ; \mathrm{LrrC}^{\mathrm{ffl} /+}(\mathrm{Het})$, or Nestin ${ }_{\mathrm{Cre} /+} ; \mathrm{LrrC}^{\mathrm{f}} \mathrm{fl}^{\mathrm{flfl}}(\mathrm{KO})$ mice.

Fig. 6. Effect of LRRC8A deletion on glutamine synthetase levels and amino acid content in the brain tissue. A, The schematic of glutamate-glutamine-GABA cycle in astrocytes and neurons . B-C, Western blots analysis of the glutamine synthetase levels in primary astrocyte cultures (B) and whole-brain lysates $(C)$, double normalized to $\beta$-actin loading and $\mathrm{fl} /+$ controls, Data are the mean values \pm SEM of 5 protein lysates for each genotype. Insets show representative western blot images for glutamine synthetase and $\beta$-actin re-probed on the same membrane. ${ }^{* * *} \mathrm{p}<0.001$, Nestin ${ }^{\mathrm{Cre} /+} ;$ Lrrc8a $^{\mathrm{fl} / \mathrm{fl}}$ knockouts (KO) vs. Lrrc8a ${ }^{\mathrm{fl} /+}$ controls (fl/++), onesample t-test with Bonferroni correction. D, HPLC analysis of the tissue levels of aspartate (D1), glutamate (D2), glutamine (D3), taurine (D4), alanine (D5), and GABA (D6) in the wholebrain lysates from four genotypes, normalized to protein levels. Data are the mean values \pm SEM of 6 mice per genotype, ${ }^{*} p<0.05,{ }^{* *} p<0.01,{ }^{* * *} p<0.001$, one-way ANOVA with Bonferroni correction.

Source data: Primary data file.

Figure supplement 6.1: Full-length western blot images for glutamine synthetase (GS) and $\beta$ actin immunoreactivity probed in lysates of primary astrocyte cultures from $L \mathrm{rrc8} \mathrm{a}^{\mathrm{fl} / \mathrm{fl}}(\mathrm{fl} / \mathrm{fl})$,

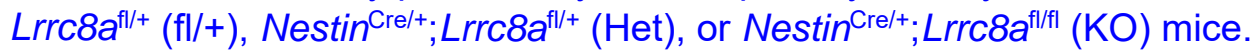

Figure supplement 6.2: Full-length western blot images for glutamine synthetase (GS) and $\beta$ actin immunoreactivity probed in whole-brain tissue lysates from $\operatorname{Lrc} 8 \mathrm{a}^{\mathrm{fl} / \mathrm{fl}}(\mathrm{fl} / \mathrm{fl}), \operatorname{Lrc} 8 \mathrm{a}^{\mathrm{fl} /+}(\mathrm{fl} /++)$, Nestin $\mathrm{Cre/+}_{;} \mathrm{LrrC}^{\mathrm{fl} / /+}$ (Het), or Nestin ${ }^{\mathrm{Cre} /+} ; \mathrm{LrrCB}^{\mathrm{fl/fl}}(\mathrm{KO})$ mice.

Figure supplement 6.2: Representative chromatogram from HPLC analysis of amino acid content in brains of $\mathrm{LrCB}^{\mathrm{fl} /++}(\mathrm{fl} /++)$, and Nestin ${ }^{\mathrm{Cre} /+} ; \mathrm{LrrCB}^{\mathrm{fl} / \mathrm{fl}}(\mathrm{LRRC} 8 \mathrm{~A} \mathrm{KO})$ mice. 


\section{References}

Abascal F. and Zardoya R. (2012) LRRC8 proteins share a common ancestor with pannexins, and may form hexameric channels involved in cell-cell communication. Bioessays 34, 551-560.

Abdullaev I. F., Rudkouskaya A., Schools G. P., Kimelberg H. K. and Mongin A. A. (2006) Pharmacological comparison of swelling-activated excitatory amino acid release and $\mathrm{Cl}$ - currents in rat cultured astrocytes. J. Physiol. 572, 677-689.

Aiba I. and Noebels J. L. (2015) Spreading depolarization in the brainstem mediates sudden cardiorespiratory arrest in mouse SUDEP models. Sci. Transl. Med. 7, 282ra46.

Albrecht J. and Schousboe A. (2005) Taurine interaction with neurotransmitter receptors in the CNS: an update. Neurochem. Res. 30, 1615-1621.

Alvestad S., Hammer J., Eyjolfsson E., Qu H., Ottersen O. P. and Sonnewald U. (2008) Limbic structures show altered glial-neuronal metabolism in the chronic phase of kainate induced epilepsy.

Neurochem. Res. 33, 257-266.

Andrew R. D. (1991) Seizure and acute osmotic change: clinical and neurophysiological aspects. J. Neurol. Sci. 101, 7-18.

Andrew R. D. and MacVicar B. A. (1994) Imaging cell volume changes and neuronal excitation in the hippocampal slice. Neuroscience 62, 371-383.

Bak L. K., Schousboe A. and Waagepetersen H. S. (2006) The glutamate/GABA-glutamine cycle: aspects of transport, neurotransmitter homeostasis and ammonia transfer. J. Neurochem. 98, 641-653.

Bao J., Perez C. J., Kim J., Zhang H., Murphy C. J., Hamidi T., Jaubert J., Platt C. D., Chou J., Deng M., Zhou M. H., Huang Y., Gaitan-Penas H., Guenet J. L., Lin K., Lu Y., Chen T., Bedford M. T., Dent S. Y., Richburg J. H., Estevez R., Pan H. L., Geha R. S., Shi Q. and Benavides F. (2018) Deficient LRRC8Adependent volume-regulated anion channel activity is associated with male infertility in mice. $\mathrm{JCl}$ Insight 3.

Binder D. K., Oshio K., Ma T., Verkman A. S. and Manley G. T. (2004) Increased seizure threshold in mice lacking aquaporin-4 water channels. Neuroreport 15, 259-262.

Chen L., Becker T. M., Koch U. and Stauber T. (2019) The LRRC8/VRAC anion channel facilitates myogenic differentiation of murine myoblasts by promoting membrane hyperpolarization. J. Biol. Chem. 294, 14279-14288.

Chowdhury G. M., Patel A. B., Mason G. F., Rothman D. L. and Behar K. L. (2007) Glutamatergic and GABAergic neurotransmitter cycling and energy metabolism in rat cerebral cortex during postnatal development. J. Cereb. Blood Flow Metab 27, 1895-1907.

Clements J. D. and Silver R. A. (2000) Unveiling synaptic plasticity: a new graphical and analytical approach. Trends Neurosci. 23, 105-113. 
Coulter D. A. and Eid T. (2012) Astrocytic regulation of glutamate homeostasis in epilepsy. Glia 60, 12151226.

Dahlstrand J., Lardelli M. and Lendahl U. (1995) Nestin mRNA expression correlates with the central nervous system progenitor cell state in many, but not all, regions of developing central nervous system. Brain Res. Dev. Brain Res. 84, 109-129.

Deneka D., Sawicka M., Lam A. K. M., Paulino C. and Dutzler R. (2018) Structure of a volume-regulated anion channel of the LRRC8 family. Nature 558, 254-259.

Dodge F. A., Jr. and Rahamimoff R. (1967) Co-operative action a calcium ions in transmitter release at the neuromuscular junction. J. Physiol 193, 419-432.

Dohare P., Hyzinski-Garcia M. C., Vipani A., Bowens N. H., Nalwalk J. W., Feustel P. J., Keller Jr R. W., Jourd'heuil D. and Mongin A. A. (2014) The neuroprotective properties of the superoxide dismutase mimetic tempol correlate with its ability to reduce pathological glutamate release in a rodent model of stroke. Free Radic. Biol. Med. 77, 168-182.

Dubois N. C., Hofmann D., Kaloulis K., Bishop J. M. and Trumpp A. (2006) Nestin-Cre transgenic mouse line Nes-Cre1 mediates highly efficient Cre/loxP mediated recombination in the nervous system, kidney, and somite-derived tissues. Genesis 44, 355-360.

During M. J., Ryder K. M. and Spencer D. D. (1995) Hippocampal GABA transporter function in temporallobe epilepsy. Nature 376, 174-177.

Eid T., Ghosh A., Wang Y., Beckstrom H., Zaveri H. P., Lee T. S., Lai J. C., Malthankar-Phatak G. H. and de Lanerolle N. C. (2008) Recurrent seizures and brain pathology after inhibition of glutamine synthetase in the hippocampus in rats. Brain 131, 2061-2070.

Eid T., Thomas M. J., Spencer D. D., Runden-Pran E., Lai J. C., Malthankar G. V., Kim J. H., Danbolt N. C., Ottersen O. P. and de Lanerolle N. C. (2004) Loss of glutamine synthetase in the human epileptogenic hippocampus: possible mechanism for raised extracellular glutamate in mesial temporal lobe epilepsy. Lancet 363, 28-37.

El I. A. and Trenkner E. (2004) Taurine as a modulator of excitatory and inhibitory neurotransmission. Neurochem. Res. 29, 189-197.

Formaggio F., Saracino E., Mola M. G., Rao S. B., Amiry-Moghaddam M., Muccini M., Zamboni R., Nicchia G. P., Caprini M. and Benfenati V. (2019) LRRC8A is essential for swelling-activated chloride current and for regulatory volume decrease in astrocytes. FASEB J. 33, 101-113.

Fricke M. N., Jones-Davis D. M. and Mathews G. C. (2007) Glutamine uptake by System A transporters maintains neurotransmitter GABA synthesis and inhibitory synaptic transmission. J. Neurochem. 102, 1895-1904.

Gaitan-Penas H., Gradogna A., Laparra-Cuervo L., Solsona C., Fernandez-Duenas V., Barrallo-Gimeno A., Ciruela F., Lakadamyali M., Pusch M. and Estevez R. (2016) Investigation of LRRC8-mediated volumeregulated anion currents in Xenopus oocytes. Biophys. J. 111, 1429-1443. 
Haj-Yasein N. N., Jensen V., Ostby I., Omholt S. W., Voipio J., Kaila K., Ottersen O. P., Hvalby O. and Nagelhus E. A. (2012) Aquaporin-4 regulates extracellular space volume dynamics during highfrequency synaptic stimulation: a gene deletion study in mouse hippocampus. Glia 60, 867-874.

Hertz L. (2013) The glutamate-glutamine (GABA) cycle: Importance of late postnatal development and potential reciprocal interactions between biosynthesis and degradation. Front Endocrinol (Lausanne) 4, 59 .

Hoffmann E. K., Lambert I. H. and Pedersen S. F. (2009) Physiology of cell volume regulation in vertebrates. Physiol. Rev. 89, 193-277.

Holthoff K. and Witte O. W. (1996) Intrinsic optical signals in rat neocortical slices measured with nearinfrared dark-field microscopy reveal changes in extracellular space. J. Neurosci. 16, 2740-2749.

Hyzinski-Garcia M. C., Rudkouskaya A. and Mongin A. A. (2014) LRRC8A protein is indispensable for swelling-activated and ATP-induced release of excitatory amino acids in rat astrocytes. J. Physiol. 592, 4855-4862.

Jentsch T. J. (2016) VRACs and other ion channels and transporters in the regulation of cell volume and beyond. Nat. Rev. Mol. Cell Biol. 17, 293-307.

Kadiyala S. B., Yannix J. Q., Nalwalk J. W., Papandrea D., Beyer B. S., Herron B. J. and Ferland R. J. (2016) Eight Flurothyl-Induced Generalized Seizures Lead to the Rapid Evolution of Spontaneous Seizures in Mice: A Model of Epileptogenesis with Seizure Remission. J. Neurosci. 36, 7485-7496.

Kang C., Xie L., Gunasekar S. K., Mishra A., Zhang Y., Pai S., Gao Y., Kumar A., Norris A. W., Stephens S. B. and Sah R. (2018) SWELL1 is a glucose sensor regulating beta-cell excitability and systemic glycaemia. Nat. Commun. 9, 367.

Kasuya G., Nakane T., Yokoyama T., Jia Y., Inoue M., Watanabe K., Nakamura R., Nishizawa T., Kusakizako T., Tsutsumi A., Yanagisawa H., Dohmae N., Hattori M., Ichijo H., Yan Z., Kikkawa M., Shirouzu M., Ishitani R. and Nureki O. (2018) Cryo-EM structures of the human volume-regulated anion channel LRRC8. Nat. Struct. Mol. Biol. 25, 797-804.

Kern D. M., Oh S., Hite R. K. and Brohawn S. G. (2019) Cryo-EM structures of the DCPIB-inhibited volume-regulated anion channel LRRC8A in lipid nanodiscs. eLife 8.

Kimelberg H. K. (2005) Astrocytic swelling in cerebral ischemia as a possible cause of injury and target for therapy. Glia 50, 389-397.

Kimelberg H. K. and Mongin A. A. (1998) Swelling-activated release of excitatory amino acids in the brain: Relevance for pathophysiology. Contrib. Nephrol. 123, 240-257.

Kumar L., Chou J., Yee C. S., Borzutzky A., Vollmann E. H., von Andrian U. H., Park S. Y., Hollander G., Manis J. P., Poliani P. L. and Geha R. S. (2014) Leucine-rich repeat containing 8A (LRRC8A) is essential for T lymphocyte development and function. J. Exp. Med. 211, 929-942.

Lagace D. C., Whitman M. C., Noonan M. A., Ables J. L., DeCarolis N. A., Arguello A. A., Donovan M. H., Fischer S. J., Farnbauch L. A., Beech R. D., DiLeone R. J., Greer C. A., Mandyam C. D. and Eisch A. J. 
(2007) Dynamic contribution of nestin-expressing stem cells to adult neurogenesis. J. Neurosci. 27, 12623-12629.

Lang F., Busch G. L., Ritter M., Volkl H., Waldegger S., Gulbins E. and Haussinger D. (1998) Functional significance of cell volume regulatory mechanisms. Physiol Rev. 78, 247-306.

Liang S. L., Carlson G. C. and Coulter D. A. (2006) Dynamic regulation of synaptic GABA release by the glutamate-glutamine cycle in hippocampal area CA1. J. Neurosci. 26, 8537-8548.

Luck J. C., Puchkov D., Ullrich F. and Jentsch T. J. (2018) LRRC8/VRAC anion channels are required for late stages of spermatid development in mice. J. Biol. Chem. 293, 11796-11808.

Magloczky Z. and Freund T. F. (2005) Impaired and repaired inhibitory circuits in the epileptic human hippocampus. Trends Neurosci. 28, 334-340.

McKenna M. C. (2007) The glutamate-glutamine cycle is not stoichiometric: fates of glutamate in brain. J. Neurosci. Res. 85, 3347-3358.

Mongin A. A. (2007) Disruption of ionic and cell volume homeostasis in cerebral ischemia: The perfect storm. Pathophysiology 14, 183-193.

Mongin A. A. (2016) Volume-regulated anion channel--a frenemy within the brain. Pflugers Arch. 468, 421-441.

Murphy T. R., Binder D. K. and Fiacco T. A. (2017) Turning down the volume: Astrocyte volume change in the generation and termination of epileptic seizures. Neurobiol. Dis. 104, 24-32.

Nilius B., Eggermont J., Voets T., Buyse G., Manolopoulos V. and Droogmans G. (1997) Properties of volume-regulated anion channels in mammalian cells. Prog. Biophys. Mol. Biol. 68, 69-119.

Okada Y. (1997) Volume expansion-sensing outward-rectifier $\mathrm{Cl}$ - channel: fresh start to the molecular identity and volume sensor. Am. J. Physiol. Cell Physiol. 273, C755-C789.

Ortinski P. I., Dong J., Mungenast A., Yue C., Takano H., Watson D. J., Haydon P. G. and Coulter D. A. (2010) Selective induction of astrocytic gliosis generates deficits in neuronal inhibition. Nat. Neurosci. 13, 584-591.

Patel A. B., de Graaf R. A., Mason G. F., Rothman D. L., Shulman R. G. and Behar K. L. (2005) The contribution of GABA to glutamate/glutamine cycling and energy metabolism in the rat cortex in vivo. Proc. Natl. Acad. Sci. U. S. A. 102, 5588-5593.

Pedersen S. F., Okada Y. and Nilius B. (2016) Biophysics and physiology of the volume-regulated anion channel (VRAC)/volume-sensitive outwardly rectifying anion channel (VSOR). Pflugers Arch. 468, 371383.

Perez E. L., Lauritzen F., Wang Y., Lee T. S., Kang D., Zaveri H. P., Chaudhry F. A., Ottersen O. P., Bergersen L. H. and Eid T. (2012) Evidence for astrocytes as a potential source of the glutamate excess in temporal lobe epilepsy. Neurobiol. Dis. 47, 331-337. 
Planells-Cases R., Lutter D., Guyader C., Gerhards N. M., Ullrich F., Elger D. A., Kucukosmanoglu A., Xu G., Voss F. K., Reincke S. M., Stauber T., Blomen V. A., Vis D. J., Wessels L. F., Brummelkamp T. R., Borst P., Rottenberg S. and Jentsch T. J. (2015) Subunit composition of VRAC channels determines substrate specificity and cellular resistance to Pt-based anti-cancer drugs. EMBO J. 34, 2993-3008.

Qiu Z., Dubin A. E., Mathur J., Tu B., Reddy K., Miraglia L. J., Reinhardt J., Orth A. P. and Patapoutian A. (2014) SWELL1, a plasma membrane protein, is an essential component of volume-regulated anion channel. Cell 157, 447-458.

Racine R. J. (1972) Modification of seizure activity by electrical stimulation. II. Motor seizure. Electroencephalogr. Clin. Neurophysiol. 32, 281-294.

Schneider C. A., Rasband W. S. and Eliceiri K. W. (2012) NIH Image to ImageJ: 25 years of image analysis. Nat. Methods 9, 671-675.

Schneider M. (2013) Adolescence as a vulnerable period to alter rodent behavior. Cell Tissue Res. 354, 99-106.

Schober A. L., Wilson C. S. and Mongin A. A. (2017) Molecular composition and heterogeneity of the LRRC8-containing swelling-activated osmolyte channels in primary rat astrocytes. J. Physiol. 595, 6939-6951.

Schousboe A., Sonnewald U. and Waagepetersen H. S. (2003) Differential roles of alanine in GABAergic and glutamatergic neurons. Neurochem. Int. 43, 311-315.

Silver R. A. (2003) Estimation of nonuniform quantal parameters with multiple-probability fluctuation analysis: theory, application and limitations. J. Neurosci. Methods 130, 127-141.

Silver R. A., Momiyama A. and Cull-Candy S. G. (1998) Locus of frequency-dependent depression identified with multiple-probability fluctuation analysis at rat climbing fibre-Purkinje cell synapses. J. Physiol 510 ( Pt 3), 881-902.

Sloviter R. S. (1987) Decreased hippocampal inhibition and a selective loss of interneurons in experimental epilepsy. Science 235, 73-76.

Strange K., Emma F. and Jackson P. S. (1996) Cellular and molecular physiology of volume-sensitive anion channels. Am. J. Physiol. 270, C711-C730.

Strange K., Yamada T. and Denton J. S. (2019) A 30-year journey from volume-regulated anion currents to molecular structure of the LRRC8 channel. J. Gen. Physiol 151, 100-117.

Svoboda J. and Sykova E. (1991) Extracellular space volume changes in the rat spinal cord produced by nerve stimulation and peripheral injury. Brain Res. 560, 216-224.

Sykova E. and Nicholson C. (2008) Diffusion in brain extracellular space. Physiol Rev. 88, 1277-1340.

Traynelis S. F. and Dingledine R. (1989) Role of extracellular space in hyperosmotic suppression of potassium-induced electrographic seizures. J. Neurophysiol. 61, 927-938. 
Tronche F., Kellendonk C., Kretz O., Gass P., Anlag K., Orban P. C., Bock R., Klein R. and Schutz G. (1999) Disruption of the glucocorticoid receptor gene in the nervous system results in reduced anxiety. Nat. Genet. 23, 99-103.

Ullrich F., Reincke S. M., Voss F. K., Stauber T. and Jentsch T. J. (2016) Inactivation and anion selectivity of volume-regulated anion channels (VRACs) depend on C-terminal residues of the first extracellular loop. J. Biol. Chem. 291, 17040-17048.

Voss F. K., Ullrich F., Munch J., Lazarow K., Lutter D., Mah N., Andrade-Navarro M. A., von Kries J. P., Stauber T. and Jentsch T. J. (2014) Identification of LRRC8 heteromers as an essential component of the volume-regulated anion channel VRAC. Science 344, 634-638.

Wang Y., Zaveri H. P., Lee T. S. and Eid T. (2009) The development of recurrent seizures after continuous intrahippocampal infusion of methionine sulfoximine in rats: a video-intracranial electroencephalographic study. Exp. Neurol. 220, 293-302.

Wehner F., Olsen H., Tinel H., Kinne-Saffran E. and Kinne R. K. H. (2003) Cell volume regulation: osmolytes, osmolyte transport, and signal transduction. Rev. Physiol. Biochem. Pharmacol. 148, 1-80.

Wilson C. S. and Mongin A. A. (2018) Cell volume control in healthy brain and neuropathologies. Curr. Top. Membr. 81, 385-455.

Yamada T. and Strange K. (2018) Intracellular and extracellular loops of LRRC8 are essential for volumeregulated anion channel function. J. Gen. Physiol. 150, 1003-1015.

Yang J., Vitery M. D. C., Chen J., Osei-Owusu J., Chu J. and Qiu Z. (2019) Glutamate-releasing SWELL1 channel in astrocytes modulates synaptic transmission and promotes brain damage in stroke. Neuron 102, 813-827.

Zhang Y., Xie L., Gunasekar S. K., Tong D., Mishra A., Gibson W. J., Wang C., Fidler T., Marthaler B., Klingelhutz A., Abel E. D., Samuel I., Smith J. K., Cao L. and Sah R. (2017) SWELL1 is a regulator of adipocyte size, insulin signalling and glucose homeostasis. Nat. Cell Biol. 19, 504-517.

Zhou C., Chen X., Planells-Cases R., Chu J., Wang L., Cao L., Li Z., Lopez-Cayuqueo K. I., Xie Y., Ye S., Wang X., Ullrich F., Ma S., Fang Y., Zhang X., Qian Z., Liang X., Cai S. Q., Jiang Z., Zhou D., Leng Q., Xiao T. S., Lan K., Yang J., Li H., Peng C., Qiu Z., Jentsch T. J. and Xiao H. (2020) Transfer of cGAMP into bystander cells via LRRC8 volume-regulated anion channels augments STING-mediated interferon responses and anti-viral immunity. Immunity doi: 10.1016/j.immuni.2020.03.016. 


\section{Wilson, Dohare et al. • Figure 1}

A
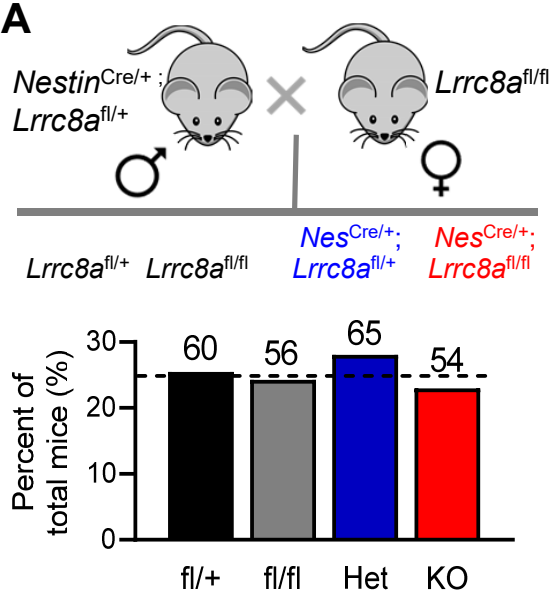

B

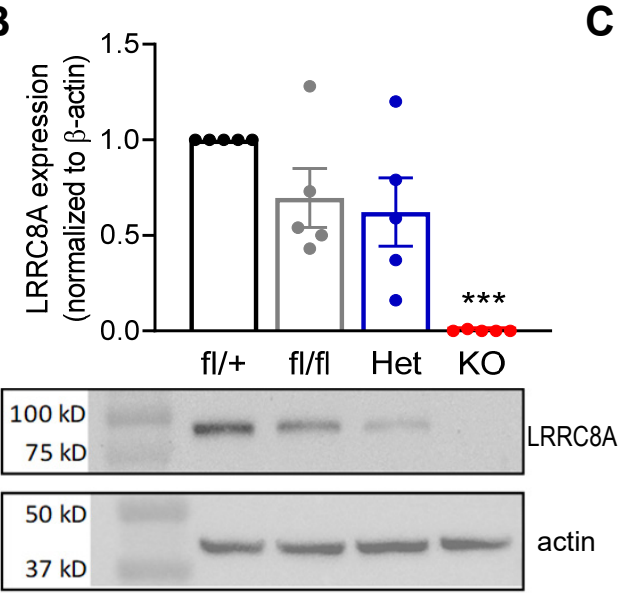

C

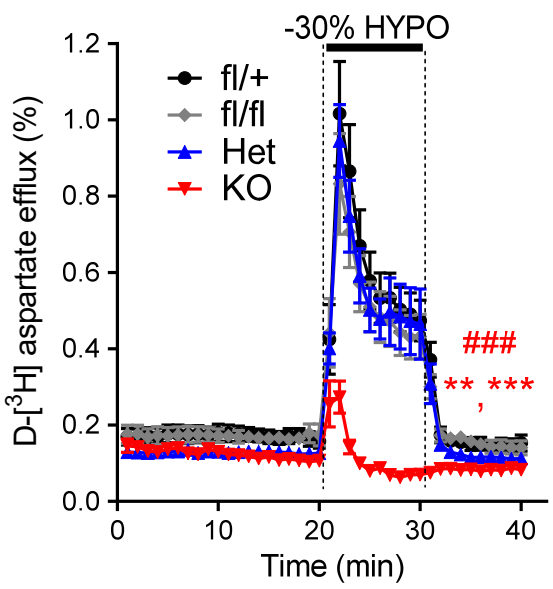

D
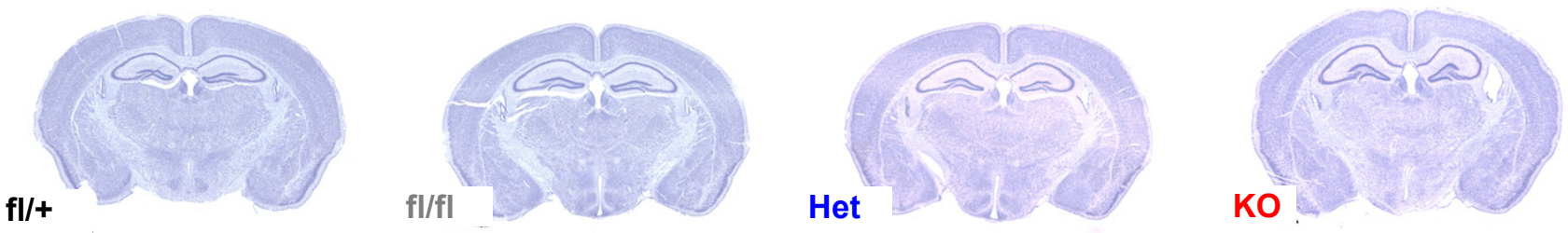

$\mathbf{E}$
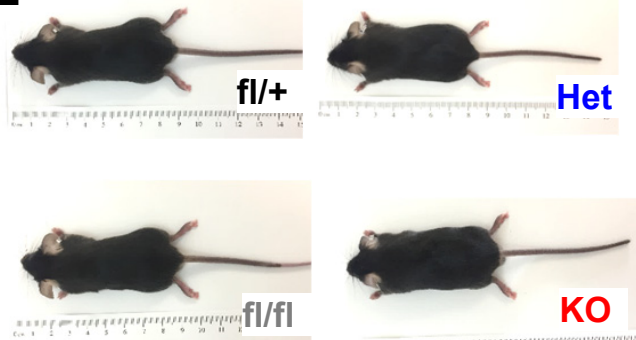

F 30

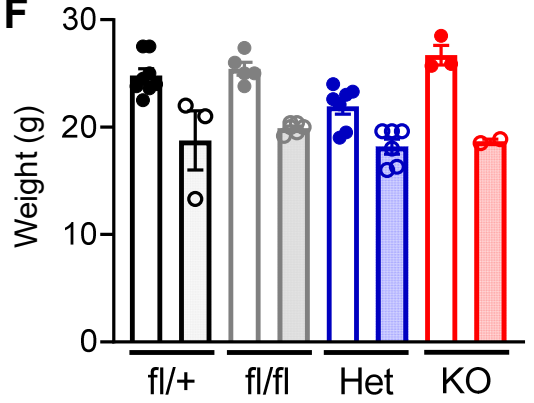

G

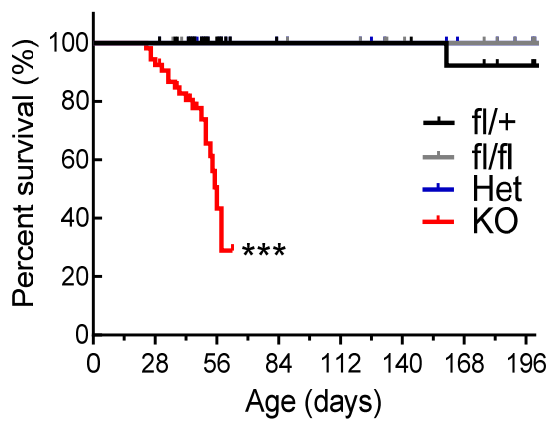

Initial characterization of animals with the brain-specific deletion of the LRRC8A protein.

A, Breeding strategy and the genotype distribution for the tissue-specific deletion of LRRC8A in the brain using $\mathrm{Nestin}^{\mathrm{Cre}}$-targeted excision of Lrrc8afl/fi. Dotted line denotes expected Mendelian ratio for all genotypes; numbers indicate the total number of animals of each genotype. B, Western blot analysis of LRRC8A protein levels in wholebrain lysates, double-normalized to $\beta$-actin and $\mathrm{fl} /+$ controls. Data are the mean values \pm SEM from 5 different animals per group. ${ }^{* * *} p<0.001$, one-sample t-test with Bonferroni correction. Lower inset shows representative western blot images for LRRC8A and $\beta$-actin re-probed on the same membranes. C, VRAC activity in primary astrocyte cultures, measured as swelling-activated $d-\left[{ }^{3} \mathrm{H}\right]$ aspartate release in response to hypoosmotic medium. Data are the mean values \pm SEM of 9 independent experiments per genotype in three different astrocyte cultures.

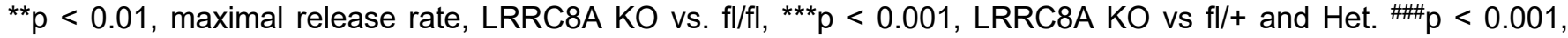
integral (10-min) release values LRRC8A KO vs. all other groups. ANOVA with Bonferroni correction. D, Representative thionin-stained brain slices used for neuroanatomical analysis ( $n=6$ per genotype). E, Representative eight-week old male mice of each genotype. F, Body weight in male and female animals of all four genotypes at 8 weeks. G, Kaplan-Meier survival curve of animals with the brain deletion of LRRC8A and their littermates. The curve is censored for animal euthanized for tissue analyses. ${ }^{* * *} p<0.001$, Log-rank (Mantel-Cox) test. 


\section{Wilson, Dohare et al. • Figure 2}

A1

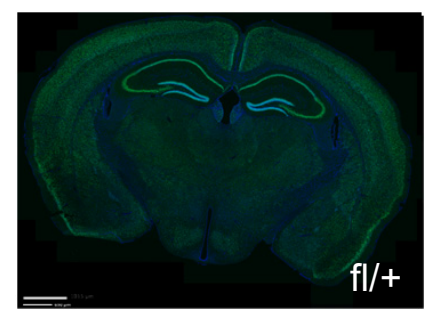

B1

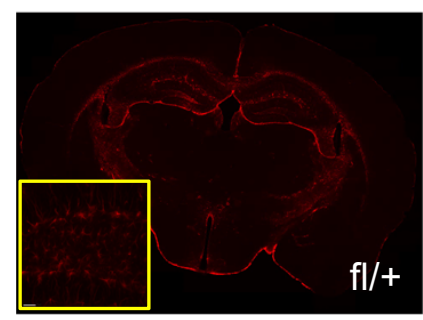

C1

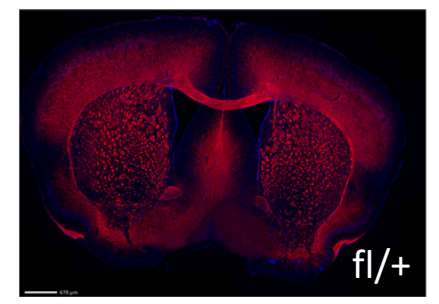

A2

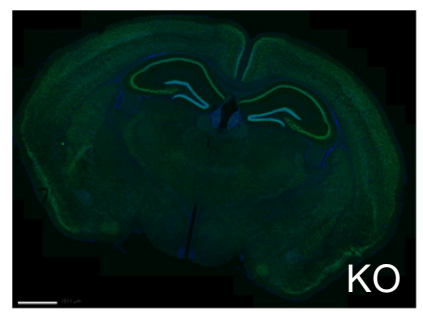

B2

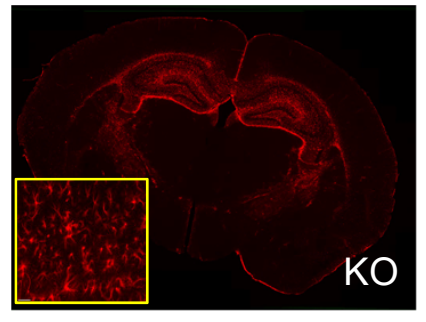

C2

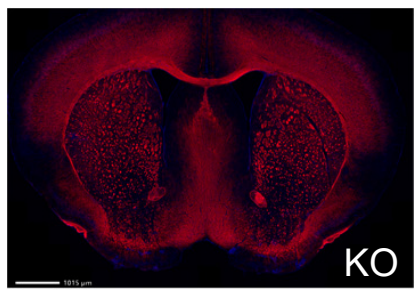

A3

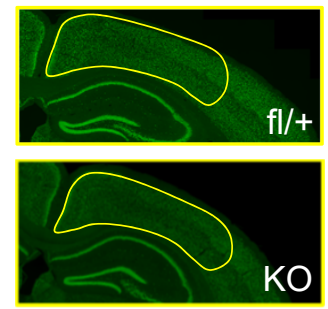

B3

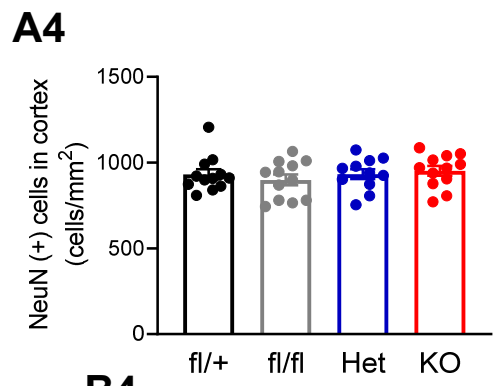

B4

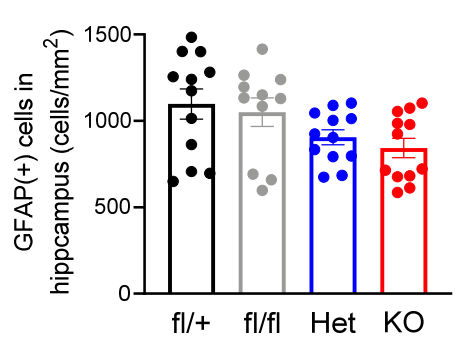

C3

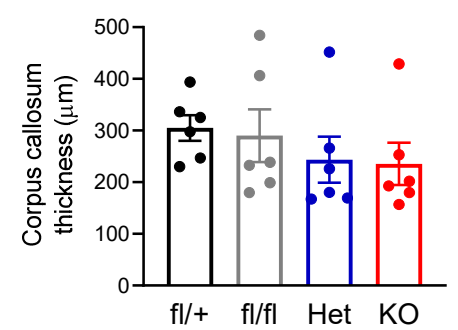

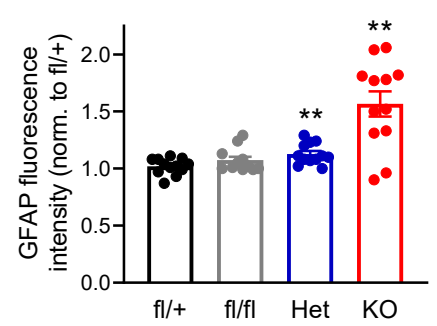

C4

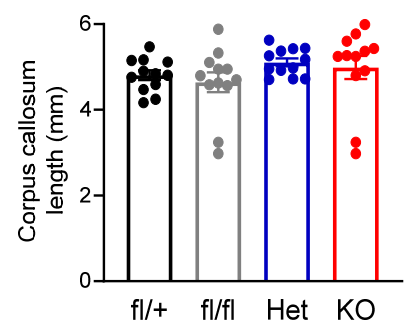

Immunohistochemical analysis of the brain cell populations targeted by the Nestincre promoter.

A, Representative images of the immunoreactivity for neuronal marker NeuN (green) and DAPI (blue) in Lrrc8a $a^{\mathrm{fl} /+}$ controls (fl/ +, A1) and Nestin ${ }^{\mathrm{Cre} /+} ; \mathrm{LrrC} \mathrm{a}^{\mathrm{fl} / \mathrm{fl}}$ knockouts $(\mathrm{KO}, \mathrm{A} 2)$ brains. Insets in A3 show the higher magnification images of NeuN signal in cortex and hippocampus. A4, Quantification of NeuN+ cell numbers in the cortical region outlined in A3. Data are the mean values \pm SEM from 6 animals per group counted bilaterally. B, Representative images and quantification of the astroglial marker GFAP (red) in hippocampal areas of $L r r c 8 a^{\mathrm{fl} /+}$ controls (fl/+, A1)

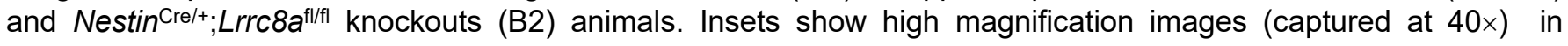
hippocampus. B3-B4, Quantification of GFAP+ cell numbers (B3) and the relative GFAP immunofluorescence (B4) in hippocampi of four genotypes. Data are the mean values \pm SEM of 6 animals per group, analyzed by one-way ANOVA with Bonferroni correction (B3) or one-sample t-test (B4). ${ }^{* *} p<0.01$, normalized KO and Het intensity vs. $\mathrm{fl} /+$ control. C, Representative immunoreactivity and quantification of the oligodendroglial marker, myelin basic protein (MBP, red) and DAPI (blue) in Lrrc8a ${ }^{\mathrm{fl} /+}$ controls $(\mathrm{fl} /+, \mathrm{C} 1)$ and Nestin ${ }^{\mathrm{Cre} /+} ; \mathrm{Lrrc} 8 \mathrm{a}^{\mathrm{fl} / \mathrm{fl}}$ knockouts knockout (KO, C2) brains. C3-C4, Quantification of corpus callosum thickness (C3) and length (C4) in four genotypes. Data are the mean values \pm SEM of 6 animals per group, measuring medial corpus callosum thickness and individual left and right lengths, analyzed by Kruskal-Wallis with Dunn's multiple comparison test. 


\section{Wilson, Dohare et al. • Figure 3}

A
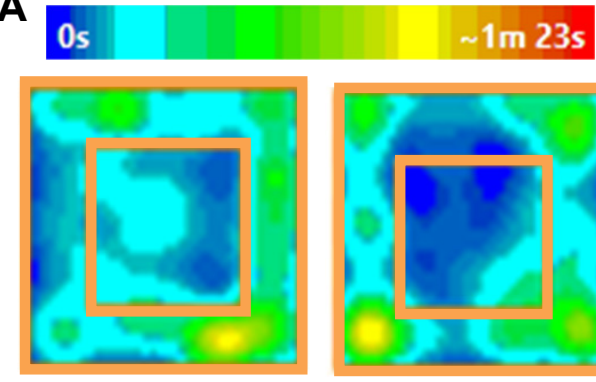

$\operatorname{Lrc8} 8 a^{\mathrm{fl} /+}$

D
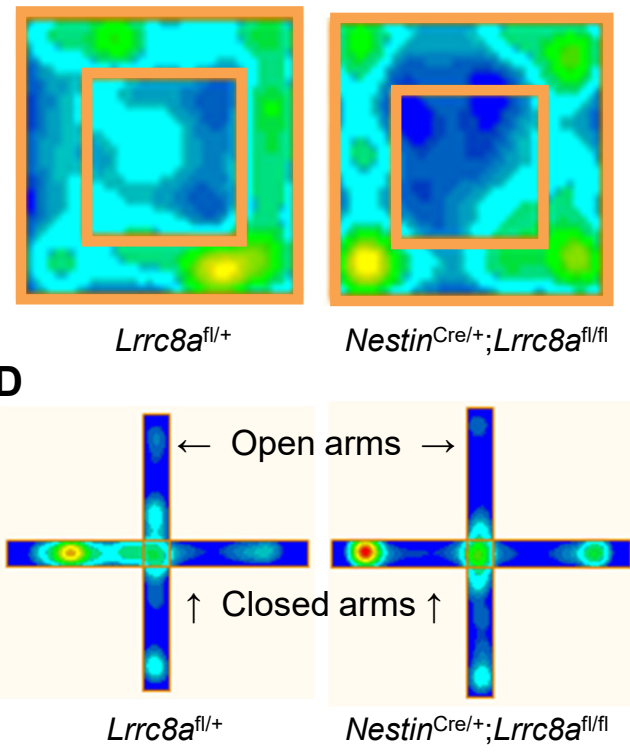

Nestin ${ }^{\mathrm{Cre} /+} ;$ Lrrc8a $\mathrm{a}^{\mathrm{fl} / \mathrm{fl}}$
B

E

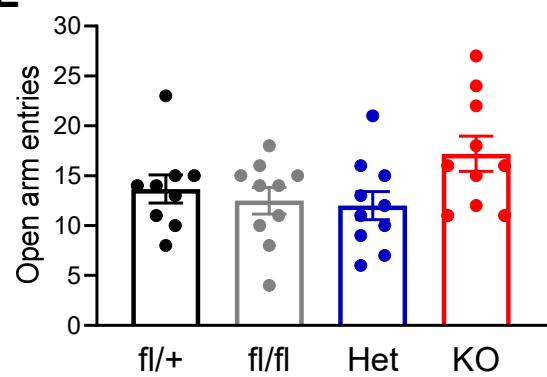

C

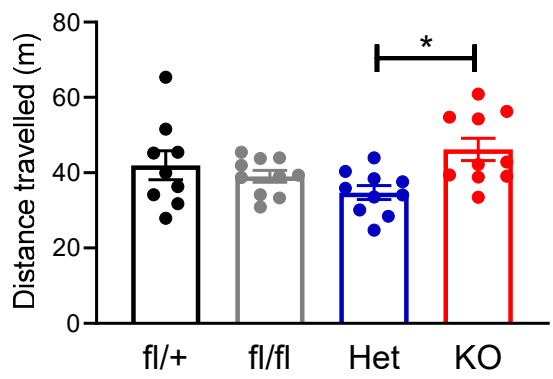

$\mathbf{F}$

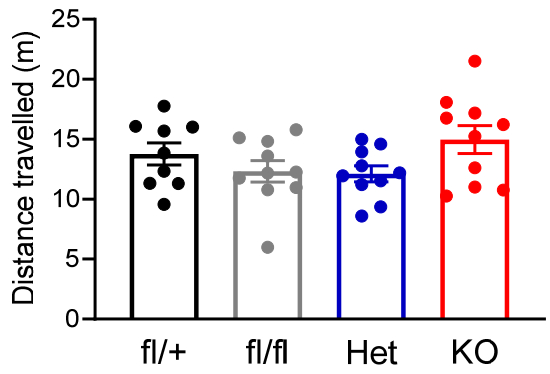

Impact of brain-specific LRRC8A deletion on animal behavior.

A, Representative heat map for control $L r r c 8 a^{f / /+}$ controls and Nestin Cre/+;Lrrc8a fl/fl knockout mice in the open field test. Color heat map indicates the amount of time spent in the center or periphery of the operant chamber. B, Percentage of the total time that the animals of for genotypes spent in the center of the open field. Data are mean

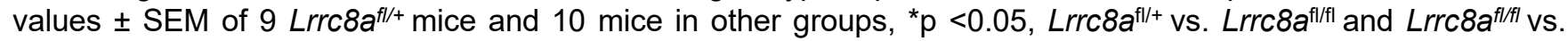

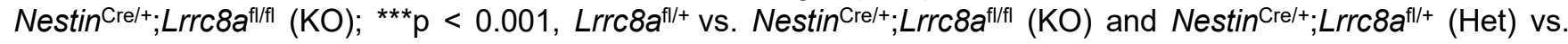
Nestin $\mathrm{Cre}^{++} ;$LrrC8a $\mathrm{a}^{\mathrm{fl} / \mathrm{fl}}(\mathrm{KO})$ analyzed by one-way ANOVA with Bonferroni correction. C, Total distance traveled during the open field test. Data are mean values \pm SEM of $9 \mathrm{Lrrc8} \mathrm{a}^{f / /+}$ mice and 10 mice in other groups. ${ }^{*} p<0.05$, $\mathrm{Nestin}^{\mathrm{Cre} /+} ; \mathrm{LrrC}^{\mathrm{fl} /++}$ (Het) vs. Nestin ${ }^{\mathrm{Cre} /+} ; \mathrm{LrrC}^{\mathrm{ffl} / \mathrm{fl}}(\mathrm{KO})$ analyzed by one-way ANOVA with Bonferroni correction. D, Representative heat maps for control Lrrc8a ${ }^{\mathrm{fl} /+}$ controls and Nestin ${ }^{\mathrm{Cre} /+} ; \mathrm{LrrC} 8 \mathrm{a}^{\mathrm{fl} / \mathrm{fl}}$ knockout mice in the elevated plus maze with two open and two closed arms. E, Number of entries into the open arm of the elevated plus maze. Data are mean values \pm SEM of $9 \mathrm{Lrrc}^{\mathrm{fl} / \mathrm{+}}$ mice and 10 mice in other groups. F, Distance traveled during the elevated plus maze trial in the same animals as in $\mathrm{E}$. 

available under aCC-BY-NC-ND 4.0 International license.

A
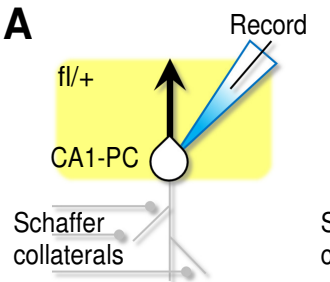

C $\mathrm{fl} /+$

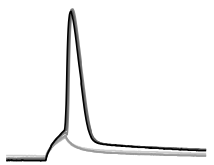

$\mathrm{KO}$

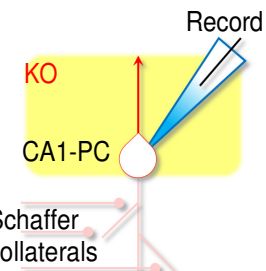

B

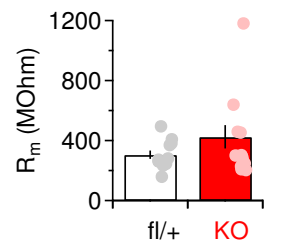

D

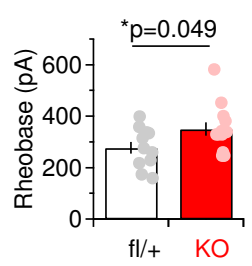

E
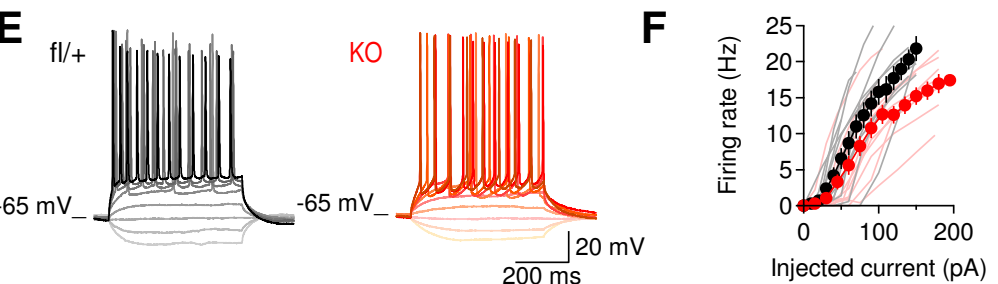
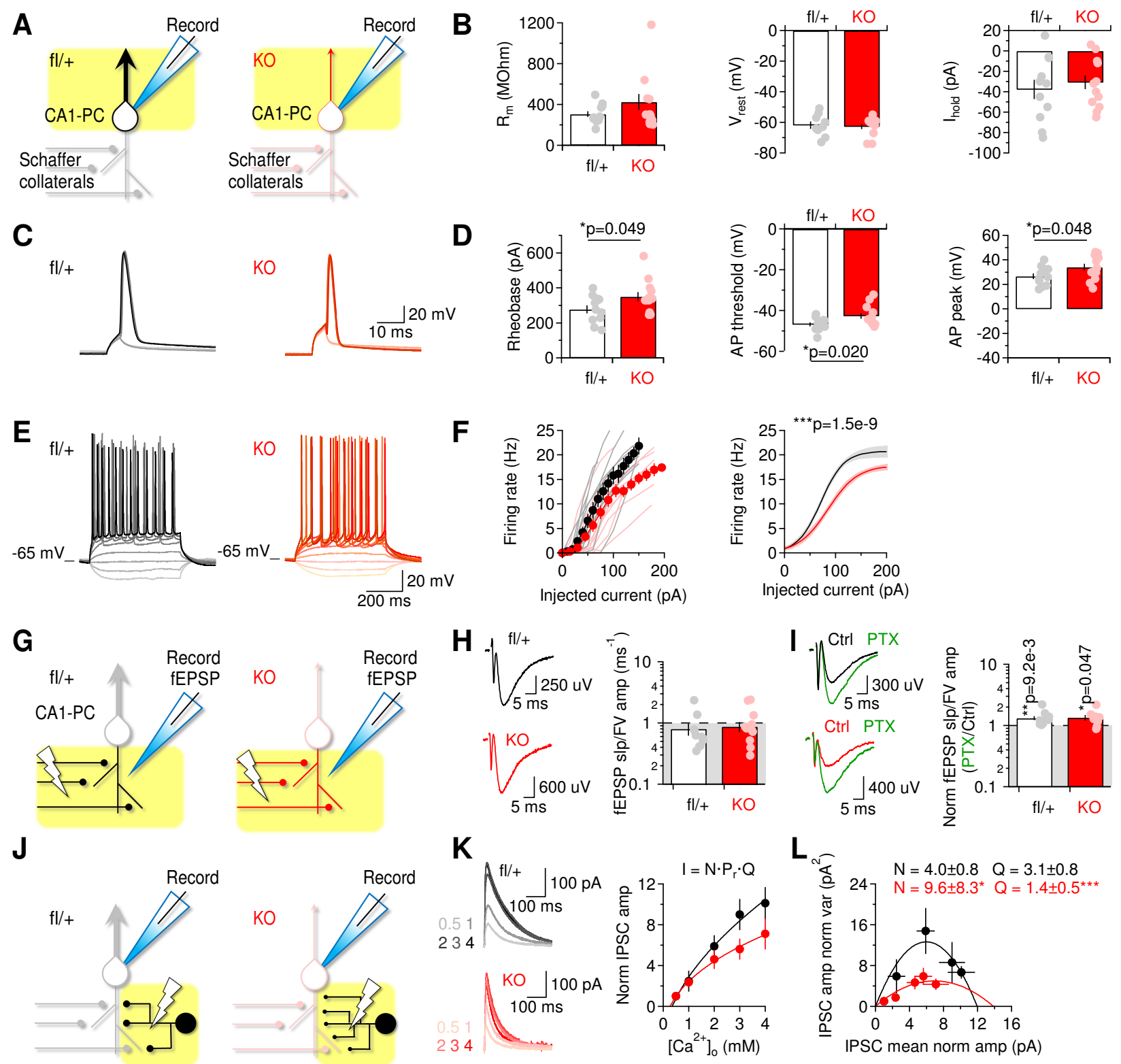

\section{Characterization of neuronal excitability in hippocampal slices of LRRC8A KO mice.}

A, Schematic of whole-cell recordings used to measure the passive and active membrane properties of CA1 pyramidal cells (PCs) in panels B-F. B, Average membrane resistance (B1), resting membrane potential (B2), and holding currents needed to maintain CA1-PCs at $-70 \mathrm{mV}(\mathrm{B} 3)$ in 9 control cells (pooled Lrrc8afl/+ [fl/+] and Lrrc8afl/fl [fl/fl]) vs. 13 LRRC8A-null (KO) cells. C, Representative action potentials recorded from CA1-PCs in response to $5 \mathrm{~ms}$ somatic current step injections of increasing amplitude. D, The average rheobase (D1), action potential threshold (D2), and action potential peak (D3) in control (fl/+ and fl/fl, $n=11)$ vs. KO cells $(n=13)$. E, Representative voltage recordings in response to $500-m s$ positive and negative current step injections in CA1-PCs. F, f/l plots showing the firing rates evoked by somatic current step injections of different amplitudes. Raw data for control slices are shown in grey. Raw data for KO are in pink. The symbols represent the average of all data collected from control (black, $n=12$ ) and KO CA1-PCs (red, $n=13)(F 1)$. F2 shows the sigmoidal fits of the data in F1. G, Schematic of stimulation and extracellular field recordings used to measure the fPSP slope and FV amplitude in panels $\mathrm{H}-\mathrm{I}$. $\mathbf{H}$, Representative recordings (left panels) from fl/+ control and KO slices. Each trace is the average of 20 consecutive recordings. The bar graph on the right) shows the mean normalized values from control $(n=11)$ and KO slices $(n=16)$. I, Representative traces (left panels) and normalized changes (right) in the field recordings in response to the GABAA blocker picrotoxin (PTX, $100 \mathrm{uM})$ in control ( $n=11$ ) and KO $(n=8)$ slices. P values indicate differences between PTX vs. no-PTX recordings in the same slices. J, Schematic of whole-cell recordings used to measure the calcium dependence of IPSC amplitude in CA1-PCs, in panels K-L. K, Representative IPSCs (left) recorded at different extracellular calcium concentrations in control and KO slices. The graph on the right displays the relationship between [Ca2+]o and the IPSC amplitude, normalized to its value at $[\mathrm{Ca} 2+] \mathrm{o}=0.5 \mathrm{mM}$ in control (fl/ $+)$ and KO slices. L, The experimentally measured relationship between variance and mean current at the peak of the IPSC. Both values were normalized to the variance and mean values at $[\mathrm{Ca} 2+] \mathrm{o}=0.5 \mathrm{mM}$. The solid curves are the parabolic fit of the data (see Methods). Data reported in this panel represent mean +/-S.D. Data included in all other panels are mean +/-S.E.M. 


\section{Wilson, Dohare et al. • Figure 5}

A

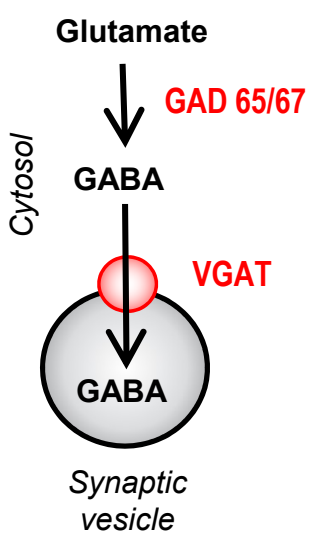

D1

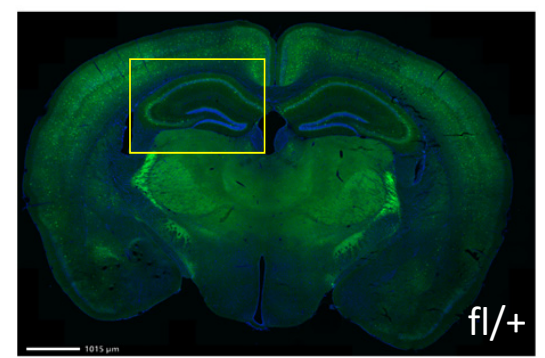

E1

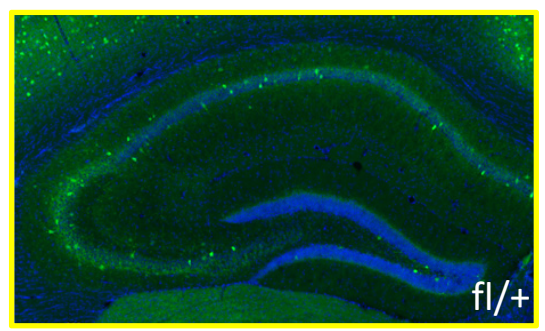

B
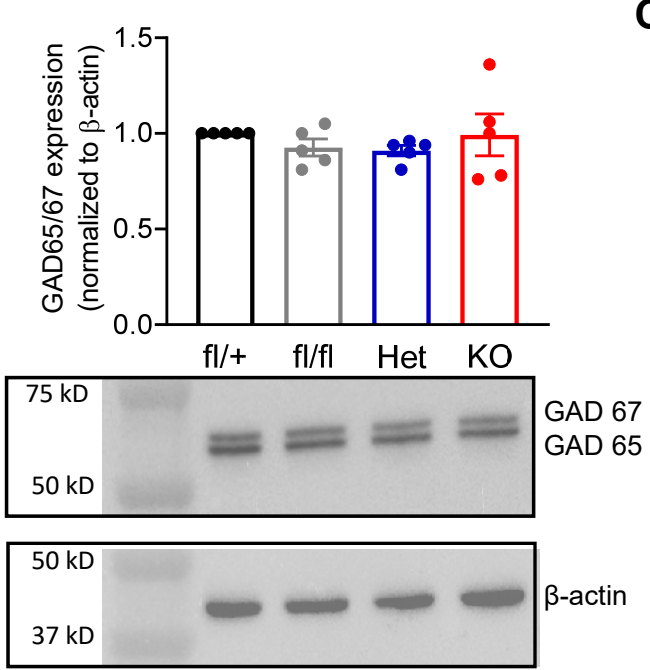

D2

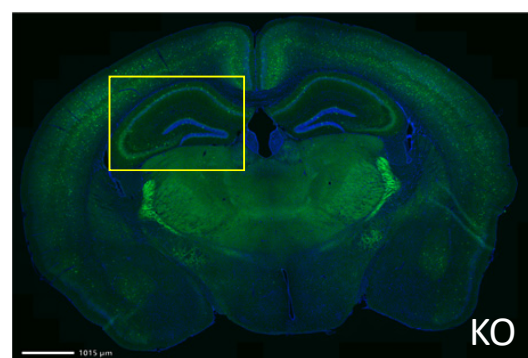

E2
KO

C
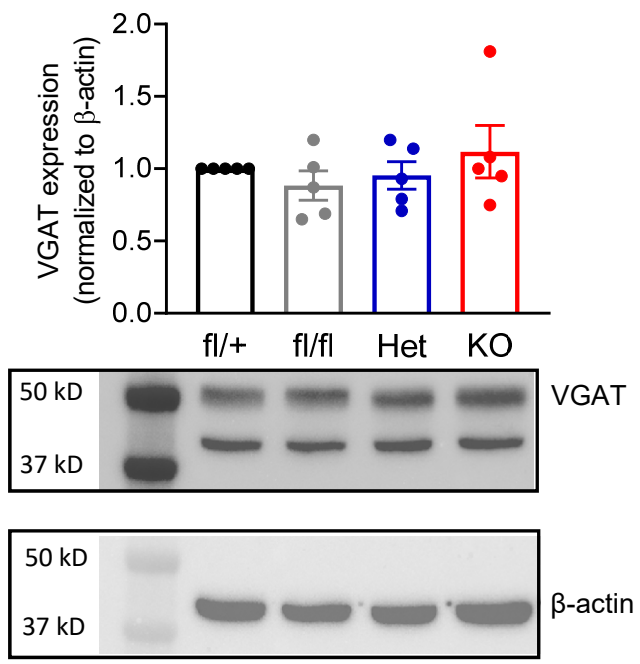

D3

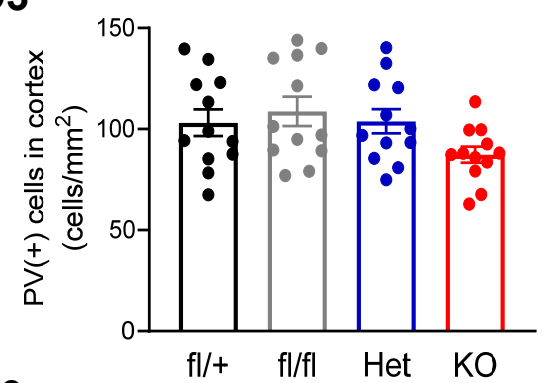

E3

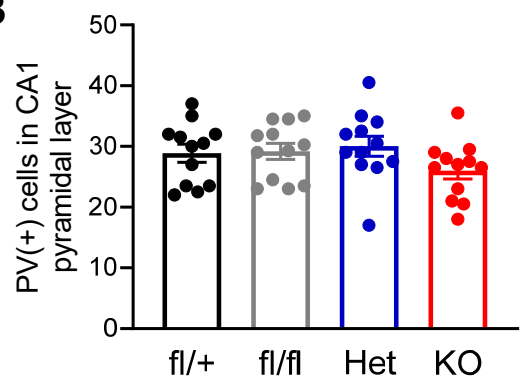

LRRC8A deletion does not impact the whole-brain GAD65/67 and VGAT protein levels and numbers of parvalbumin-positive interneurons in hippocampus and cortex.

A, The schematic of GABA synthesis and packaging in GABAergic cells. B, Western blot analysis of GAD65/67 protein levels in the whole-brain lysates. C, Western blot analysis of VGAT protein levels in the whole-brain lysates. In $B$ and $C$, the data are the mean values \pm SEM of immunoreactivity in 5 brain lysates per group double normalized to $\beta$-actin and fl/+ control. Inset shows representative western blot images for GAD 65/67, VGAT, and matching $\beta$-actin loading controls on the same membrane. D, Representative immunohistochemistry images of parvalbumin-positive (green) and DAPI (blue) stained brain slices in Lrrc8a ${ }^{\mathrm{fl} /+}$ controls (fl/+, D1) and $\mathrm{Nestin}^{\mathrm{Cre} /+} ; \mathrm{LrrCB}^{\mathrm{fl} / \mathrm{fl}}$ (KO, D2) brains. D3, Number of parvalbumin-positive cells in medial cortex. Data are the mean values \pm SEM of 6 animals per genotype, quantified bilaterally. E, Magnified images and quantification of the parvalbumin immunohistochemistry signal in the hippocampal regions outlined by yellow box in D1 and D2, respectively. E3, Number of parvalbumin+ cells in CA1 pyramidal layer. Data are the mean values \pm SEM of 6 animals per genotype, quantified bilaterally. 
Wilson, Dohare et al. • Figure 6

A

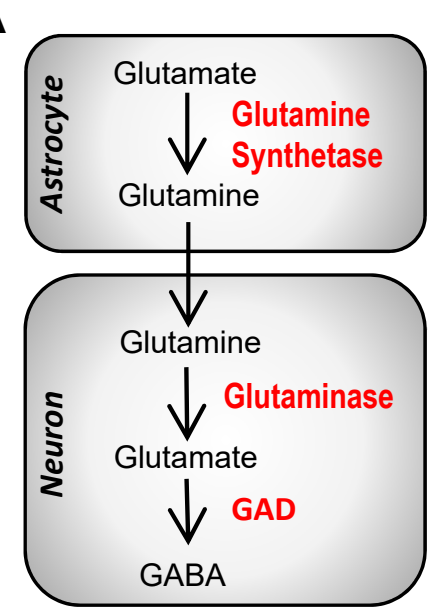

D1

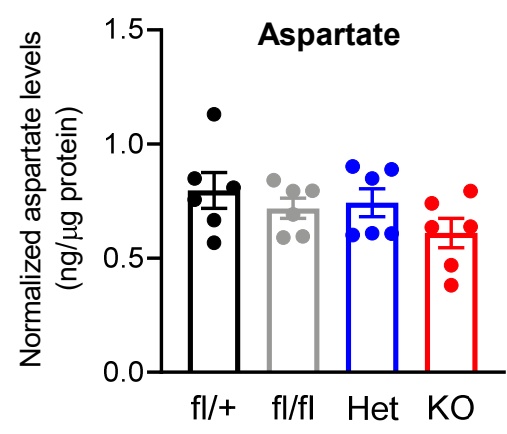

D4

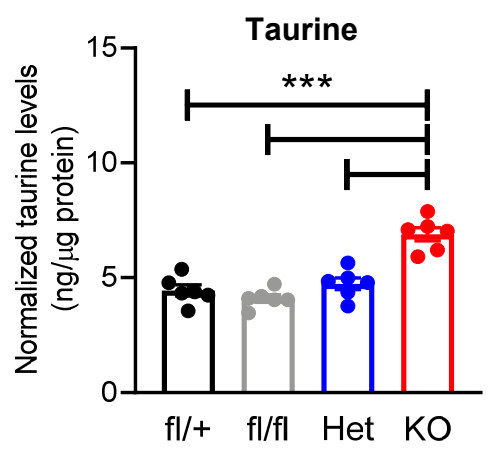

B
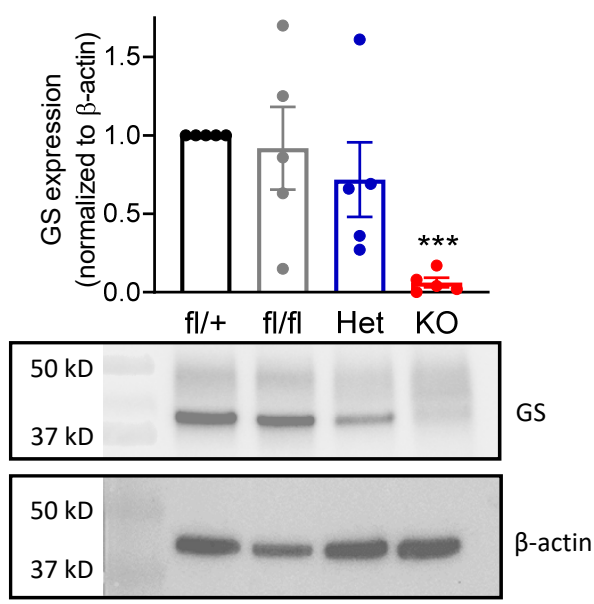

\section{D2}

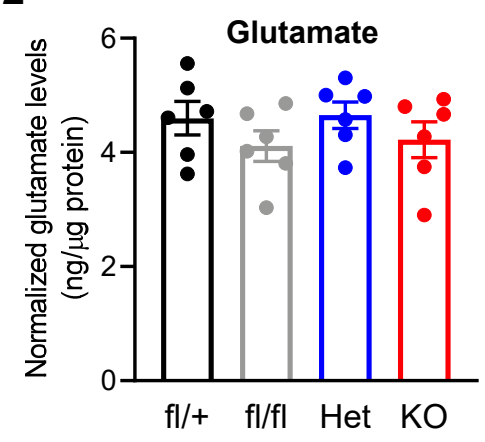

D5

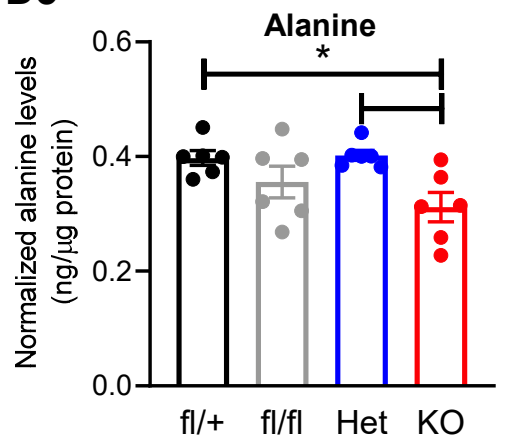

C
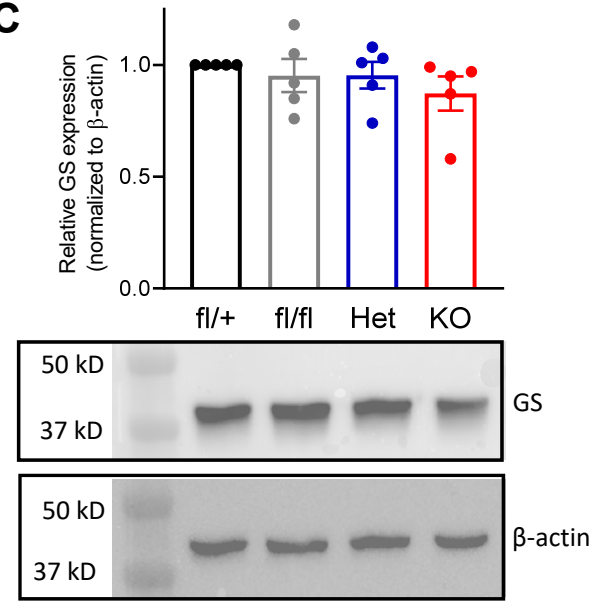

\section{D3}

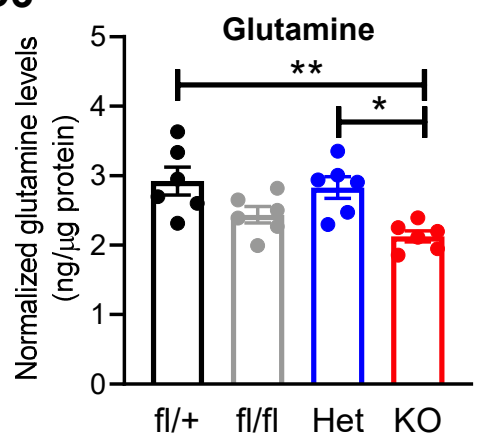

D6

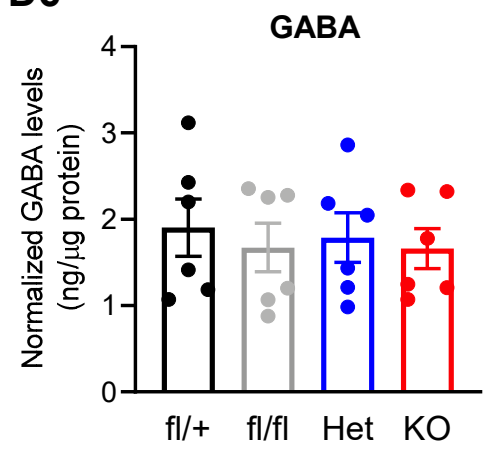

Effect of LRRC8A deletion on glutamine synthetase levels and amino acid content the brain tissue.

A, The schematic of glutamate-glutamine-GABA cycle in astrocytes and neurons. B-C, Western blots analysis of the glutamine synthetase levels in primary astrocyte cultures $(B)$ and whole-brain lysates (C), double normalized to $\beta$-actin loading controls and $\mathrm{fl} /+$. Data are the mean values \pm SEM of 5 protein lysates for each genotype. Insets show representative western blot images for glutamine synthetase and $\beta$-actin re-probed on the same membrane. ${ }^{* * *} \mathrm{p}<0.001$, Nestin ${ }^{\mathrm{Cre} /+} ;$ Lrrc8a $a^{\mathrm{fl} / \mathrm{ll}}$ knockouts (KO) vs. Lrrc8a $a^{\mathrm{fl} /+}$ controls (fl/+), one-sample t-test with Bonferroni correction. D, HPLC analysis of the tissue levels of aspartate (D1), glutamate (D2), glutamine (D3), taurine (D4), alanine (D5), or GABA (D6) in the whole-brain lysates from four genotypes, normalized to protein levels. Data are the mean values \pm SEM of 6 independent animals per genotype, ${ }^{*} p<0.05,{ }^{* *} p<0.01,{ }^{* * *} p<0.001$, one-way ANOVA with Bonferroni correction. 